\title{
Stress Transfer and Seismic Phenomena in Coupled Subduction Zones During the Earthquake Cycle
}

\author{
Renata Dmowska and James R. Rice \\ Division of Applied Sciences and Department of Earth and Planetary Sciences \\ Harvard University, Cambridge, Massachusetts \\ Lucia C. Lovison and Daniel Josell \\ Division of Applied Sciences, Harvard University, Cambridge, Massachusetts
}

\begin{abstract}
An elementary mechanical model of a coupled subduction zone is presented. It is used to study the transfer of extensional stresses along the underthrusting plate, and shear stress interactions between the plate itself and its thrust contact zone with the overriding plate, during the earthquake cycle. The model assumes an elastic plate which deforms one dimensionally, has shear drag interactions (treated approximately by the Elsasser procedure) with a Maxwellian viscoelastic mantle, and is subject to steady gravitational sinking forces. Great thrust earthquakes are simulated as sudden stress-relieving displacements at the contact zone between the slab and overriding plate. The model allows analysis of the spaceand time-variable stresses in the main thrust zone, the adjacent oceanic plate, and the subducting slab over each earthquake cycle. Stress variations leading to outer-rise events are discussed, as well as stress changes responsible for intraplate seismicity downdip from the main thrust zone, based on simulations of periodic great earthquakes. The results of simulated slow progression of deformation (slip) from below into the thrust contact zone are also presented. Such preslip, occurring over a time scale that is small in comparison with the whole seismic cycle (e.g., of the order of a tenth or so), is shown to transiently slow the rate of buildup of, or even relieve, extensional stresses in the slab. In the absence of preslip those stresses build up steadily in time during the latter part of the cycle. The results have implications for induction of sesimic quiescence as well as for explaining patterns of seismicity in relation to spatial position along the underthrusting plate and to time throughout the cycle. Correlations are reported between the model simulations and seismicity observations from coupled subduction zones around the world. The observations include tensional outer-rise events after large subduction earthquakes and compressional ones in the latter parts of the cycle, normal (tensional) intraplate earthquakes preceding the main thrust events and positioned downdip from the thrust zones, and interlaced periods of seismic activity in the lower part of the main thrust zone and in the descending slab.
\end{abstract}

\section{INTRODUCTION}

The concept of large earthquakes repeating themselves along coupled subduction zones has long been recognized [Fedotov, 1965] and used as the basis underlying seismic gap predictions [e.g., Mogi, 1969, 1979; Kelleher, 1970, 1972; Sykes, 1971; Utsu, 1972; Kelleher et al., 1973; Ohtake et al., 1977; McCann et al., 1979]. However, its logical development into the idea of earthquake cycles (though usually of different recurrence interval and very often of different length of the main rupture as well) has been slower and has occurred only in recent years [Gonzalez et al., 1984; McNally and GonzalezRuiz, 1986; Dmowska et al., 1986; Astiz and Kanamori, 1986; Christensen and Ruff, 1983; Korrat and Madariaga, 1986; Spence, 1987]. The distinction is that the notion of a seismic gap involves, essentially, only the area of main thrust earthquake. By comparison, that of an earthquake cycle encompasses space- and time-dependent phenomena occurring not only in the zone of the main subduction event but also downdip from that zone, including intraplate seismicity in the descending and overriding slabs [e.g., Shimazaki, 1978] and phenomena in the nearby oceanic plate, including outer-rise events. It includes the time variation of stress and hence seismicity in all such regions, especially complex seismicity patterns in the area of the future main shock, including eventual quiescence. All these phenomena are linked together by the

Copyright 1988 by the American Geophysical Union.

Paper number 7B6066.

0148-0227/88/007B-6066\$05.00 underlying mechanism of subduction of the descending slab, moderated and opposed by frictional forces arising from contact with the overriding continental plate and from motion relative to the mantle.

As a result of the episodic motion of the subducting slab, of which the upper part is locked and slides only in the main event, and of the gravitationally driven sinking of the lower parts of the slab, stresses pulsate in time throughout the cycle, with stress transfer interactions occurring between different regions of the slab and its surroundings. We present here an elementary model of such stress accumulation and transfer. Before doing that we briefly review the observational basis for such modeling, using our own observations as well as those reported by others and concentrating on the interactions between the thrust contact zone and the subducting plate.

\section{Interactions Between Loading Processes} AND SEISMicity IN COUPLed Subduction ZoNeS

To better understand the stress redistribution in space and time during the earthquake cycle along the downgoing, gravitationally sinking slab and its zone of contact with the overriding continental plate, as well as in the oceanic plate adjacent to the area of the main subduction event, we report here some observational evidence from coupled subduction zones around the world.

\subsection{Extensional Intraplate Earthquakes}

The direct evidence of tensional stresses acting in the downgoing slab in the latter portions of the earthquake cycle, 


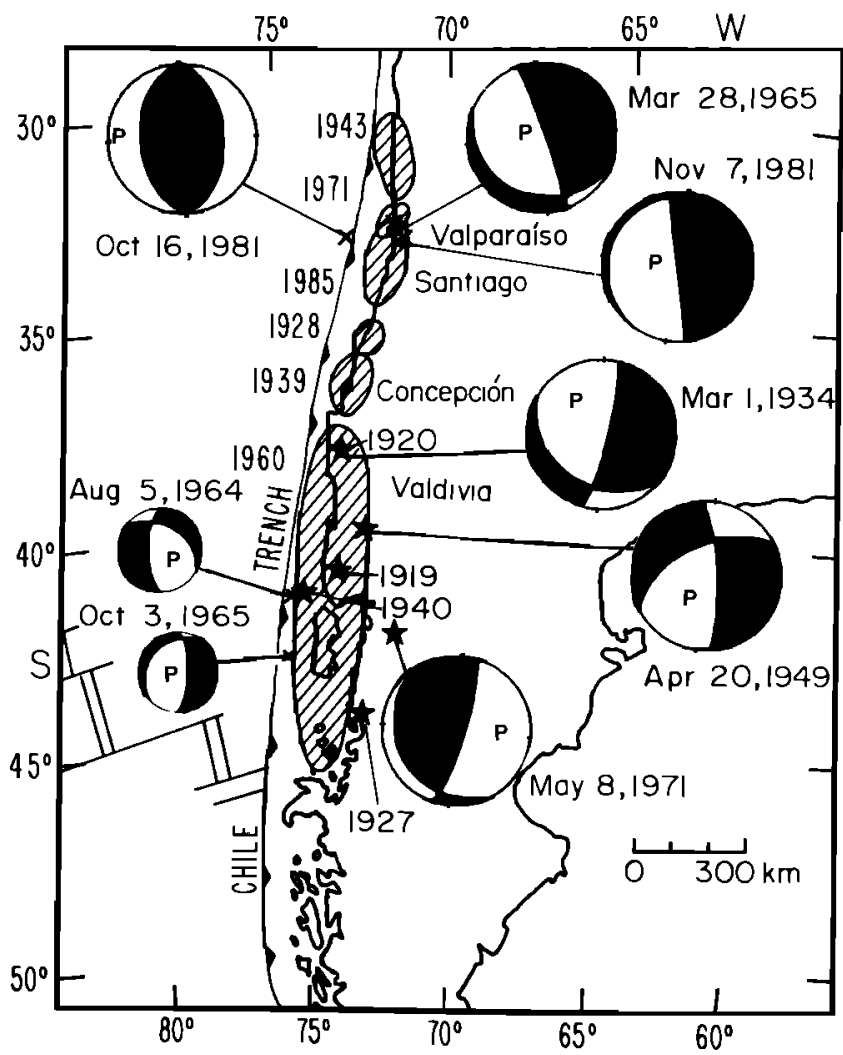

Fig. 1. Sequence of events for Chilean earthquakes of May 21, 1960, La Ligua earthquake of July 9, 1971, and Valparaiso earthquake of March 3, 1985 [after Astiz and Kanamori, 1986].

at depths starting from just below the zone of thrust earthquakes and reaching $200-250 \mathrm{~km}$ depth, is the occurrence of normal, extensional earthquakes in many zones around the world. These intermediate-term precursory phenomena show that this particular part of the subduction zone entered the mature stage of the cycle, though how mature is difficult to assess, as this kind of seismicity might happen 15 years before the main event (as in the Middle American Trench [Gonzalez et al., 1984; McNally and Gonzalez-Ruiz, 1986]) or occur only a few months before the great subduction earthquake (e.g., before the Michoacan 1985 earthquake [McNally et al., 1986]). The presence of large normal earthquakes, downdip from interface thrust zones, that preceded large gap-filling subduction events has been reported for Chile [Malgrange and Madariaga, 1983; Astiz and Kanamori, 1986] and Peru [Dewey and Spence, 1979; Beck and Ruff, 1984]. Dmowska et al. [1986] presented a simple mechanical model of subduction in coupled subduction zones, rationalizing the existence of such earthquakes. Lovison [1986] identified such earthquakes before recent large subduction events in the Middle American Trench area. McNally et al. [1986] investigated the presence of normal events before the Michoacan 1985 earthquake.

Also, geodetic data from different subduction zones in Japan suggest that slip occurs at depths downdip from the interface thrust zones before great earthquakes. The presence of such slowly acting slip is also evidence of tensional stresses occurring deeper in the slab before great subduction earthquakes; this has been discussed and modeled by Thatcher and Rundle [1979, 1984].

Here we will list some additional observational evidence concerning large normal earthquakes occurring before gapfilling subduction events.
1. In the region of La Ligua in north central Chile, an event of March 28, 1965, on a steeply dipping normal fault preceded by 6 years the large thrust event of July 9, 1971 [Malgrange et al., 1981] (see Figure 1).

2. The large underthrust Valparaiso event of March 3, 1985 , was preceded by a normal fault earthquake on November 7, 1981 [Dziewonski and Woodhouse, 1983; Astiz and Kanamori, 1986] (see Figure 1).

3. Fault plane solutions of April 20, 1949, and March 1, 1934, intermediate-depth earthquakes are consistent with steeply dipping normal faults and suggest downdip tensional stress [Astiz and Kanamori, 1986]; both events occurred before the May 21, 1960, Chilean earthquake (Figure 1).

4. Seven months before the Ometepec doublet of June 7, 1982 (Middle American Trench zone), a normal earthquake with $m_{b}=6.3$ occurred downdip, at about a 70-km depth [Lovison, 1986] (see Figures 9 and 10).

5. In the region of Colima (Middle American Trench zone) a normal earthquake occurred on February 27, 1966, preceding by 7 years the main underthrust event of January 30, 1973 [Lovison, 1986] (see Figures 7 and 8).

6. The area downdip of the Playa Azul (October 25, 1981) and Michoacan (September 19, 1985) earthquakes in Mexico shows extensional seismicity on and off for 2-9 years before the Playa earthquake [Lovison, 1986; McNally et al., 1986] and a normal event with $m_{b}=5.2$ that occurred 3.7 months before the Michoacan event, $100 \mathrm{~km}$ downdip from the main event [McNally et al., 1986]. See Figures 5 and 6.

\subsection{Outer-Rise Earthquakes}

We will now look for possible signs of space- and timedependent stresses during the whole earthquake cycle in the outer-rise zones, that is, zones of oceanic lithosphere adjacent to subduction regions. The areas of outer rise are thought to be under bending stresses [Chapple and Forsyth, 1979; Forsyth, 1982; Chen and Forsyth, 1978; Ward, 1983, 1984]. However, as pointed out by Christensen and Ruff [1983], these areas are also showing signs of stresses related to spatiotemporal variation of activity of interplate thrust earthquakes. For coupled subduction zones the outer-rise events are compressional prior to large subduction zone earthquakes [Christensen and Ruff, 1983] and tensional after large subduction events, as the tensional stress from slab pull is temporarily transmitted to the outer rise. We are inclined to assume, on the basis of our modeling and observations, that the additional pulsating tension-compression stresses associated with earthquake cycles (see later discussion) are perhaps sufficient to cause the observed change of mechanism of outer-rise events. The magnitude of the pulsating stresses might not be very large, but they superpose on the more or less steady bending stresses which may be near to conditions for either extensional or compressional failure at different depths.

First, let us note here that only tensional outer-rise events are found for uncoupled subduction zones (Kermadec, Java, New Hebrides, Marianas, and Izu-Bonin [Christensen and Ruff, 1983]), suggesting that the slab there is constantly under tension due to the slab pull. The only exception is the TongaKermadec Trench, which has both tensional and compressional events [Christensen and Ruff, 1983].

As Christensen and Ruff [1983] note, about $60 \%$ of the known tensional outer-rise events occur in the coupled zones. Of the 34 tensional events in coupled zones, at least 28 occurred after large subduction events. Twenty-three of those 
events occurred within a 15 -year period following some of the largest subduction events in recent history (Rat Islands, 1965, five events; Aleutian Islands, 1957, six events; Kurile Islands, 1963, four events; Chile, 1960, five events; Alaska, 1964, one event; Kamchatka, 1952, one event; and Hokkaido, 1952, one event).

One more extensional (normal) outer-rise event is reported by Korrat and Madariaga [1986], namely the event of September 25, 1971, in Chile, occurring oceanward of the large subduction event of July 9, 1971.

For compressional outer-rise events we make the following observations:

1. On October 16, 1981, and February 25, 1982, there were two compressional outer-rise events oceanward of the 1906 earthquake zone in Chile, the cycle in this place being closed by the Valparaiso subduction event of March 3, 1985 [Korrat and Madariaga, 1986]. The time span between the outer-rise events and the underthrust main earthquake is 4 and 3 years, respectively.

2. Also in Chile, oceanward and north of the 1922 rupture zone, there was a compressional outer-rise event on August 18, 1964 [Christensen and Ruff, 1983], with $m_{b}=6.1$. We searched this area for further events, and we found that on August 3, 1978, there was an intermediate-depth normal earthquake with $m_{b}=6.3$ (depth of $49 \mathrm{~km}$, from the International Seismological Centre (ISC) catalog), downdip from the main zone of thrust subduction earthquakes. This was followed on October 4, 1983, by a main thrust event, closing the cycle in this part of the subduction boundary $\left(m_{b}=6.4\right.$, depth of $15 \mathrm{~km}$, from the U.S. Geological Survey (USGS) catalog). The sequence, and the 10-day aftershock area for the main event, are presented in Figure 2.

3. Oceanward of the Kurile Islands gap there were two compressional outer-rise events, on March 16, 1963, and December 2, 1971 [Christensen and Ruff, 1983].

4. In the Tonga-Kermadec Islands region there was a compressional outer-rise event on July 2, 1974, followed by an underthrust doublet on January 14, 1976 [Christensen and Ruff, 1983]. The time span between these earthquakes is $\mathbf{1 . 5}$ years.

5. It is plausible that the October 11,1940 , earthquake in southern Chile is a compressional outer-rise event [Astiz and Kanamori, 1986], which occurred 20 years before the large May 21, 1960, Chile earthquake.

\subsection{Loading Episodes, Interactions Along Slab and Quiescence}

Now we turn to more subtle seismicity observations on loading episodes, that is, trends of updip progression of seismicity during the whole earthquake cycle, that are cited in subsections 2.1 and 2.2. In our pursuit of observations concordant with the idea of stresses pulsating during the whole earthquake cycle in the mode suggested by our modeling and, also, with the idea of progressive loading of the locked thrust zone coming from below and caused by the sinking slab, we will concentrate here on ephemeral phenomena of seismicity patterns of small earthquakes $\left(m_{b} \geq 4.0\right)$, treating their occurrence as a kind of stress gauge, that is, as a sign of higher stresses in the area. Here we would not claim that the observed seismic patterns indicate unambiguously the stress transfers and interactions taking place in the subduction process. However, it does appear that they can be interpreted in a manner which is not discordant with the general notions of

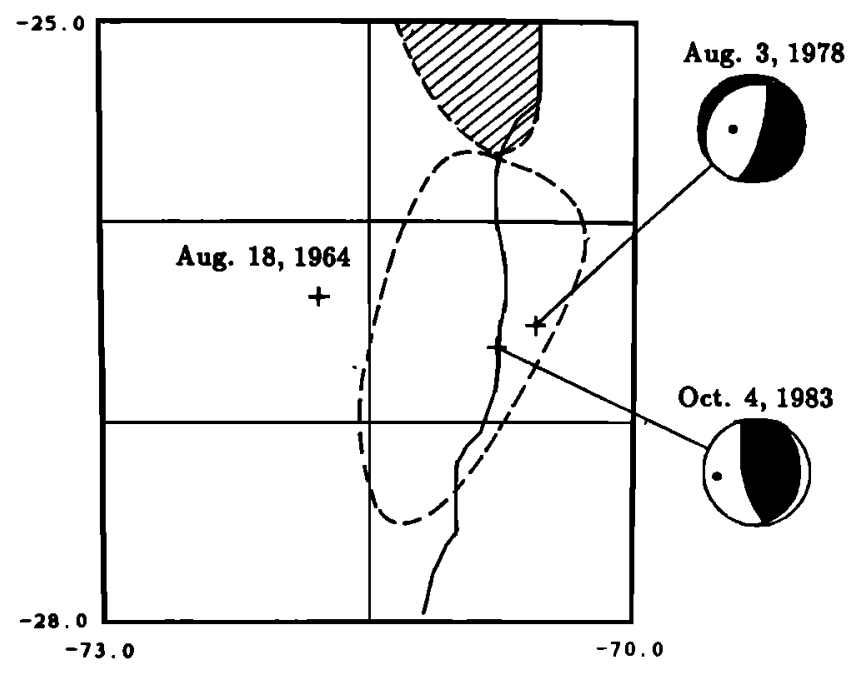

Fig. 2. Sequence of events for northern Chile earthquake of October $4,1983\left(m_{b}=6.4\right)$.

stressing processes in our modeling, especially with notions of progression of loading from downdip to the thrust zone during the later half or so of the cycle and of stress interactions between preslip in the thrust zone and transient unloading of the descending slab, possibly related to intervals of quiescence there. Our data come from recently assembled observations on different zones of large earthquakes in the Middle American Trench [Lovison, 1986]. We are using the ISC catalog up to December 1984, and the preliminary determination of epicenters catalog subsequently, for earthquakes with $m_{b} \geq 4.0$. We show the seismicity for each case in the plot of epicentral distance from the trench versus time, for space windows hugging the aftershock zones of main underthrust events and going downdip, along the subducting slab.

Figure 3 presents the area of the Petatlan earthquake of March 14, $1979\left(m_{b}=6.3\right)$, for earthquakes with $m_{b} \geq 4.0$ and the time window of January 1, 1964, to October 31, 1986. The aftershock zone of the Petatlan earthquake is marked. The dotted line surrounds the area of our search, of which the results are shown in Figure 4.

In this figure the seismicity is presented in the plot of epicentral distance from the trench versus time. The period of higher activity in the downdip zone coincides here with quiescence updip (for the period up to 1969), which is followed by the activation of the updip zone, close to the area of the future main event, for the period 1969-1975. This latter period is much more quiet in the downdip zone. Then the area downdip gets activated again (in 1976), with quiescence updip, followed by a foreshock sequence in the updip area, preceding the main event. The observed pattern of activity shows how the loading from downdip seems to activate the updip zone, and how activity updip can perhaps transiently unload the slab.

Figure 5 shows the setting of our search for seismicity patterns associated with the Playa Azul earthquake of October 25, $1981\left(m_{b}=6.3\right)$, of which results are presented in Figure 6, again in the plot of epicentral distance from the trench versus time. In the period shown before the main event it appears that when the downdip zone of normal earthquakes is active the updip thrust zone is quiet and vice versa. Also, there is relative seismic quiescence in the thrust zone prior to the main event. 


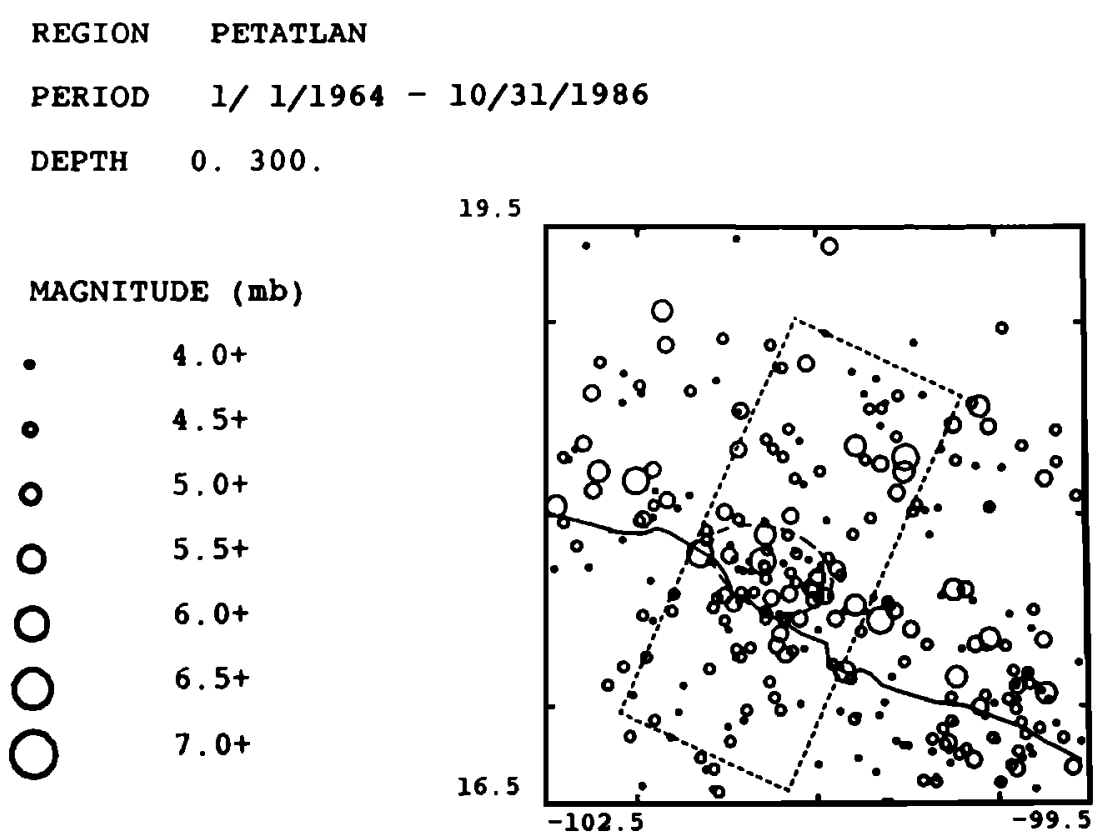

Fig. 3. Seismicity in the area of Petatlan (Mexico) for the time period January 1, 1964, to October 31, 1986. The dotted line surrounds the area of our search, and the dashed line shows the aftershock zone of the Petatlan earthquake of March $14,1979\left(m_{b}=6.3\right)$.

Figure 7 shows our search area for seismicity patterns associated with the Colima earthquake of January 3, 1973, of which results are presented in Figure 8. Here, for the limited period covered before the main event the downdip area of normal earthquakes is slightly active, with some seismicity in the lower thrust zone of the main event, and then the downdip area turns quiet, with seismicity concentrated in the thrust zone updip. This is followed by quiescence, lasting for 23 months.

Figure 9 shows the setting of our search for seismicity patterns associated with the Ometepec double earthquakes of
June 7, 1982, and Figure 10 presents the results. There is a relative quiescence in the area of the future event for the period May 1975 to January 1979 (44 months), with few earthquakes happening during that time, all with $m_{b} \leq 5$. Before that period, during 1971-1972, the area updip shows a mixture of normal and thrust events (the mechanisms are shown whenever known).

These and other observations of seismicity patterns for large subduction events in Mexico [Lovison, 1986] encourage us to hypothesize that at least in some cases the equivalent of a concentrated deformation front (modeled later as preslip)

\section{REgION PETATLAN \\ DISTANCE VERSUS TIME}

$\begin{array}{ll}\text { MAGNITUD } \\ . & 4.0 \\ - & 4.5 \\ \circ & 5.0 \\ \circ & 5.5 \\ \% & 6.0 \\ \% & 6.5 \\ \% & 7.0\end{array}$

$(\mathrm{mb})$

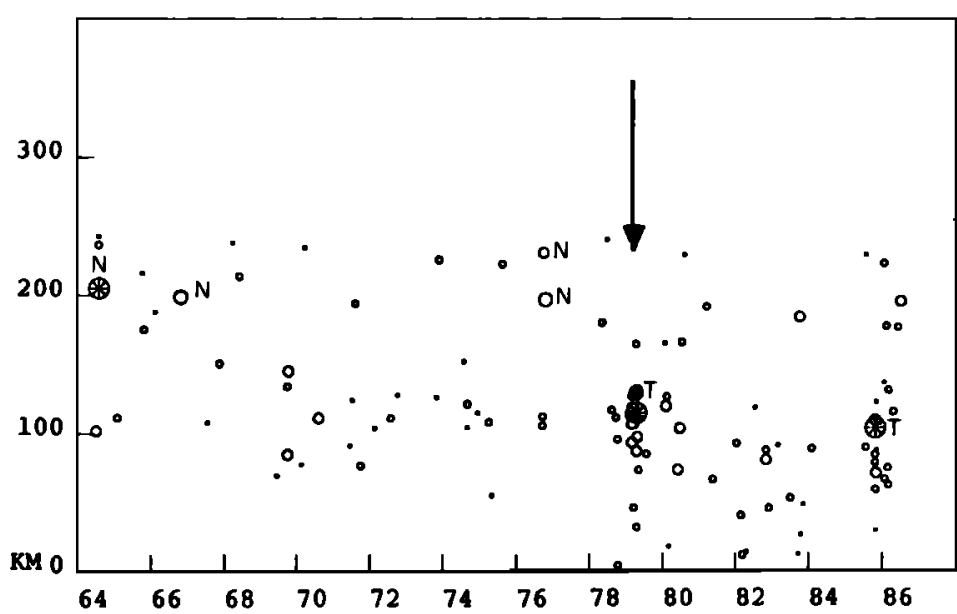

Fig. 4. Seismicity from the area of Petatlan (Mexico) for the time period January 1, 1964, to October 31, 1986, shown in the plot of epicentral distance from the trench versus time. The arrow marks the main Petatlan earthquake of March 14, 1979. Focal mechanisms are shown when known: $T$ denotes thrust, and $\mathrm{N}$ normal faulting. 

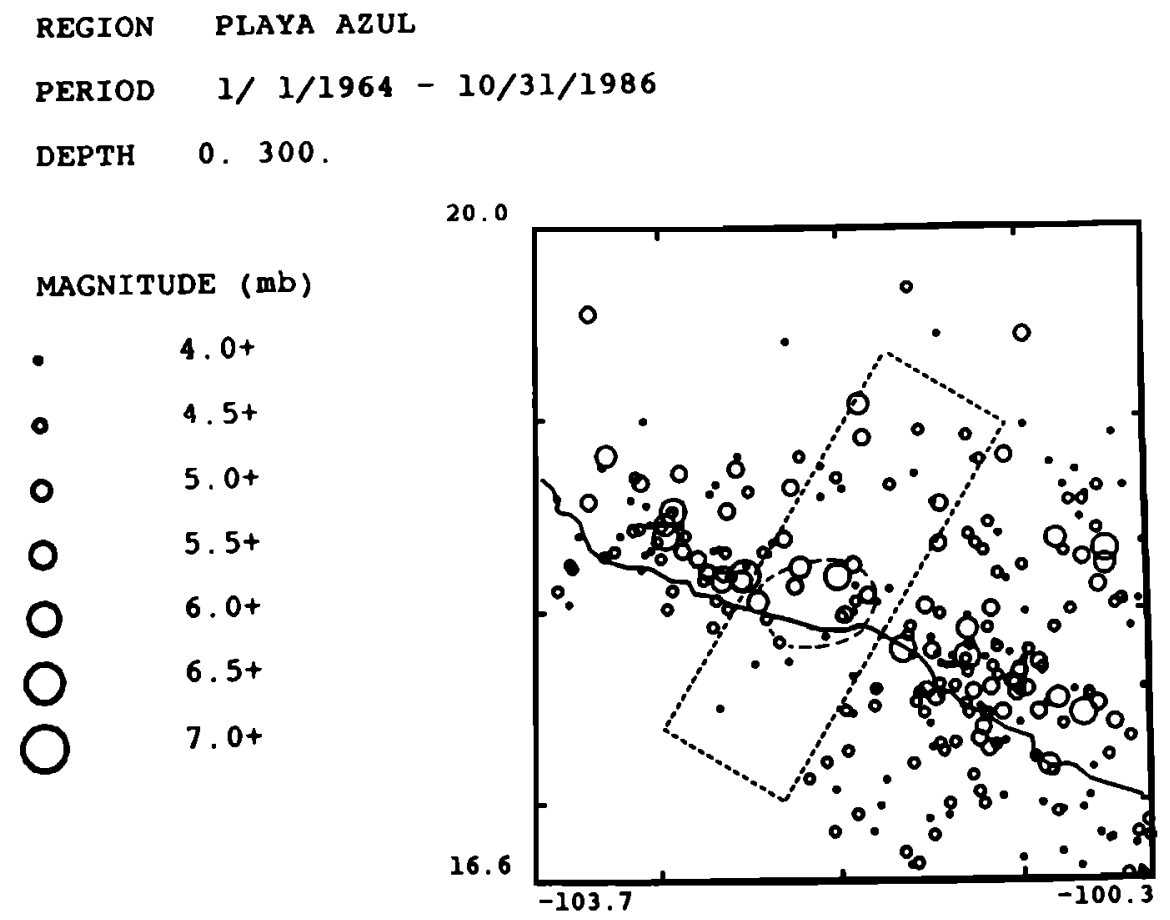

Fig. 5. Seismicity in the area of Playa Azul (Mexico) for the time period January 1, 1964, to October 31, 1986. The dotted line surrounds the area of our search, and the dashed line shows the aftershock zone of the Playa Azul earthquake of October 25, $1981\left(m_{b}=6.3\right)$.

enters, from below, the thrust zone of the future large earthquake. It relieves stress there as it progresses upward and manifests itself as seismic activity. If big enough, such preslip could, as suggested by our modeling, significantly but transiently lower the stresses in the slab downdip of the thrust zone, causing quiescence there. Also, the appearance of normal events just below that zone which we presume to undergo preslip (as observed for the Ometepec area around 1972, Figure 10 ) can be rationalized by local extensional stress con- centrations in the slab below such a progressing deformation front. Continued gravitationally, gradually this process rebuilds shear stress on the now quieter thrust zone.

\section{Elementary Model of Stress Accumulation aNd TRANSFer in COUPLed SUbduction ZoNeS DuRING THE EARThQuAKe CYCLE}

Models of stress accumulation and transfer in coupled subduction zones during the earthquake cycle are usually directed

\section{REGION PLAYA AZUL}

DISTANCE VERSUS TIME

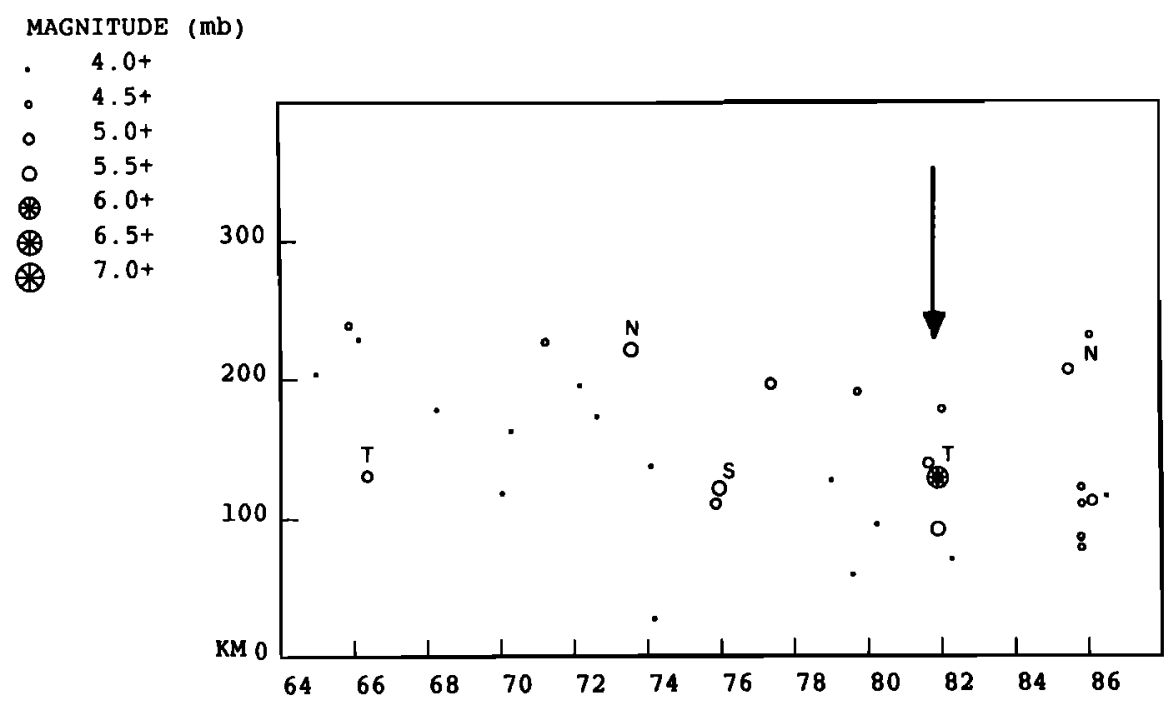

YEARS

Fig. 6. Seismicity from the area of Playa Azul (Mexico) for the time period January 1, 1964, to October 31, 1986, shown in the plot of epicentral distance from the trench versus time. The arrow marks the Playa Azul earthquake of October 25, 1981. Focal mechanisms are shown when known; $\mathbf{S}$ denotes strike-slip faulting. 


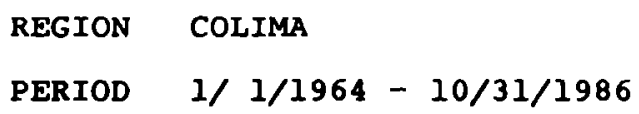

\section{MAGNITUDE (mb)}

$\begin{array}{ll}- & 4.0+ \\ - & 4.5+ \\ 0 & 5.0+ \\ 0 & 5.5+ \\ 0 & 6.0+ \\ 0 & 6.5+ \\ 0 & 7.0+\end{array}$

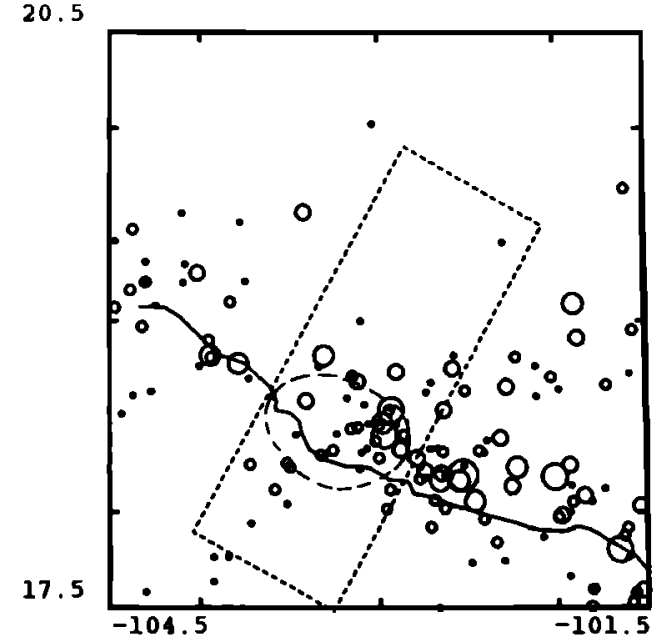

Fig. 7. Seismicity in the area of Colima (Mexico) for the time period January 1, 1964, to October 31, 1986. The dotted line surrounds the area of our search, and the dashed line shows the aftershock zones of the Colima earthquake of January $30,1973\left(m_{b}=6.1\right)$.

to the area of main thrust event, with consideration of the near-trench areas on one side of such zones and the overriding continental plate on the other. They have been constructed primarily for comparisons with geodetic observations of space- and time-variable surface deformation in the regions of great subduction earthquakes [Fitch and Scholz, 1971; Nur and Mavko, 1974; Smith, 1974; Bishke, 1974; Scholz and Kato, 1978; Melosh and Fleitout, 1982; Melosh and Raefsky, 1983; Savage, 1983; Thatcher and Rundle, 1979, 1984]. Some of the models have involved dislocated elastic layers over viscoelastic half-spaces. Their purpose is to understand the slow deformation processes in zones of great subduction events and thus to gain an insight into the recurrence of large earthquakes.

The model we present here encompasses the deformation of a larger area, namely the oceanic crust adjacent to the zone of large subduction earthquakes, the thrust zone itself, and the part of the downgoing slab to depths of around $200-250 \mathrm{~km}$, that is, before it enters the zone of higher resistance from the surrounding mantle. It specifically treats the underthrusting plate as a stress guide. The model is an extremely simple one,

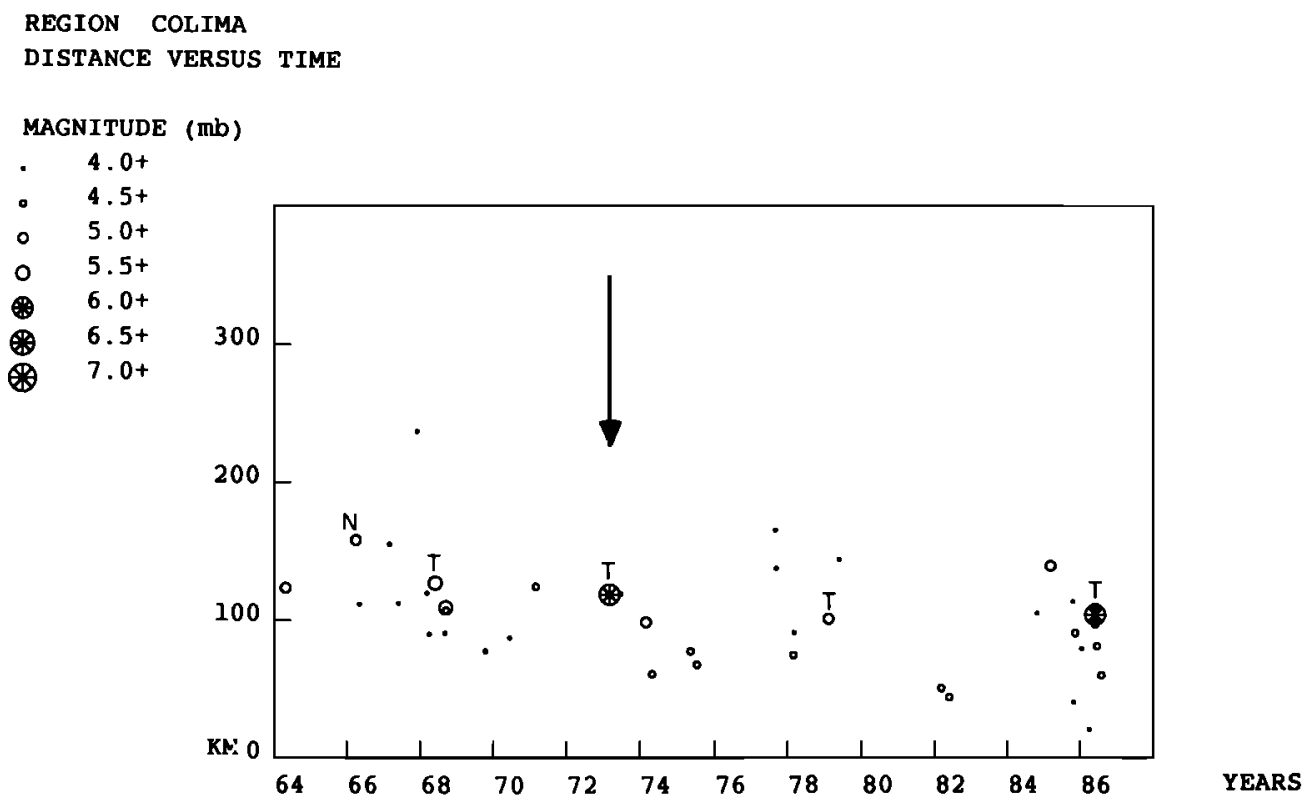

Fig. 8. Seismicity from the area of Colima (Mexico) for the time period January 1, 1964, to October 31, 1986, shown in the plot of epicentral distance from the trench versus time. The arrow marks the Colima earthquake of January $30,1973$. Focal mechanisms are shown when known. 


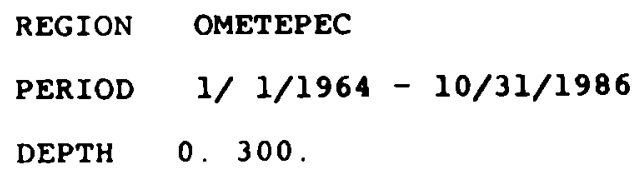

$\begin{array}{cc}\text { MAGNITUDE (mb) } \\ - & 4.0+ \\ 0 & 4.5+ \\ 0 & 5.0+ \\ 0 & 5.5+ \\ 0 & 6.0+ \\ 0 & 6.5+ \\ 0 & 7.0+\end{array}$

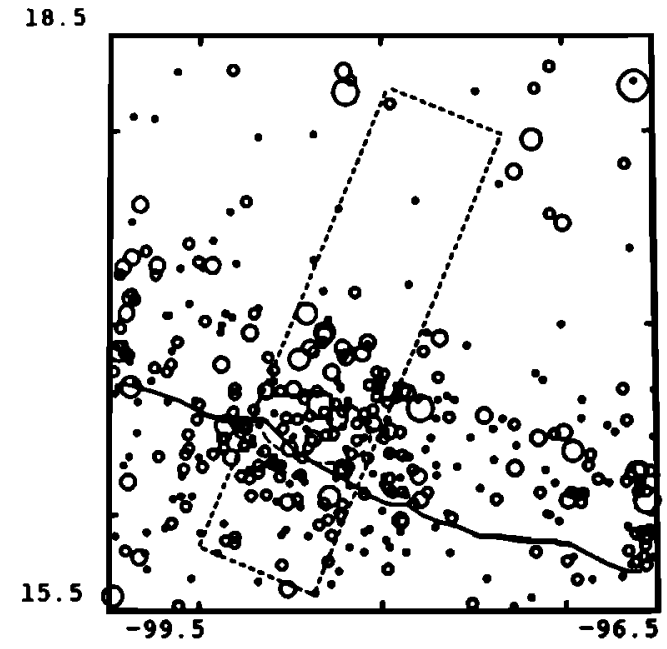

Fig. 9. Seismicity in the area of Ometepec (Mexico) for the time period January 1, 1964, to October 31, 1986. The dotted line surrounds the area of our search, and the dashed line shows the aftershock area of the Ometepec double earthquakes of June 7, $1982\left(m_{b}=6.0\right.$ and 6.3$)$.

but it accounts for several important features associated with the earthquake cycle and allows us to gain some insight into interactions between different parts of the slab. We seek correlations between our model predictions and seismicity observations from around the world, as reported in the previous section.

Figure $11 a$ shows the oceanic lithosphere with the thickness $H$ dipping under the continental plate and into the asthenosphere, with average velocity $V_{p l}$. The subduction process is intermittent in that the locked cool brittle contact zone be- tween the downgoing slab and the overriding continental plate unlocks completely only in great thrust earthquakes.

The locked contact zone undergoes a transition to a more ductile shear zone, which broadens into an asthenosphere between the descending slab and the overriding continental plate. This picture encompasses the downgoing slab up to the depth where the sinking motion is more or less constant: at greater depths the asthenosphere is thought to resist the sinking even more as the slab thickens.

Observe that the fields of stresses $\sigma_{i j}$ and displacement rates

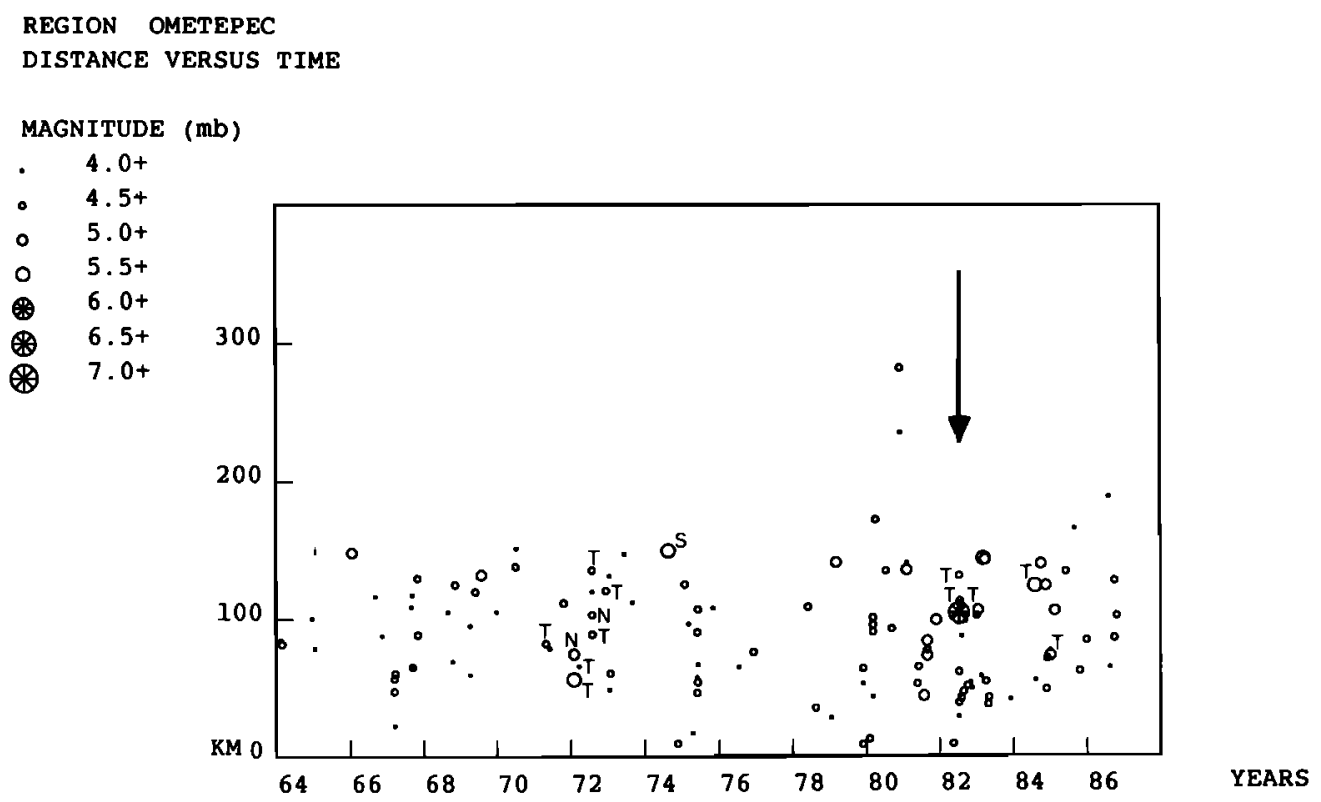

Fig. 10. Seismicity from the area of Ometepec (Mexico) for the time period January 1, 1964, to October 31, 1986, shown in the plot of epicentral distance from the trench versus time. The arrow marks the Ometepec doublet of June 7 , 1982. Focal mechanisms are shown when known. 
(a)

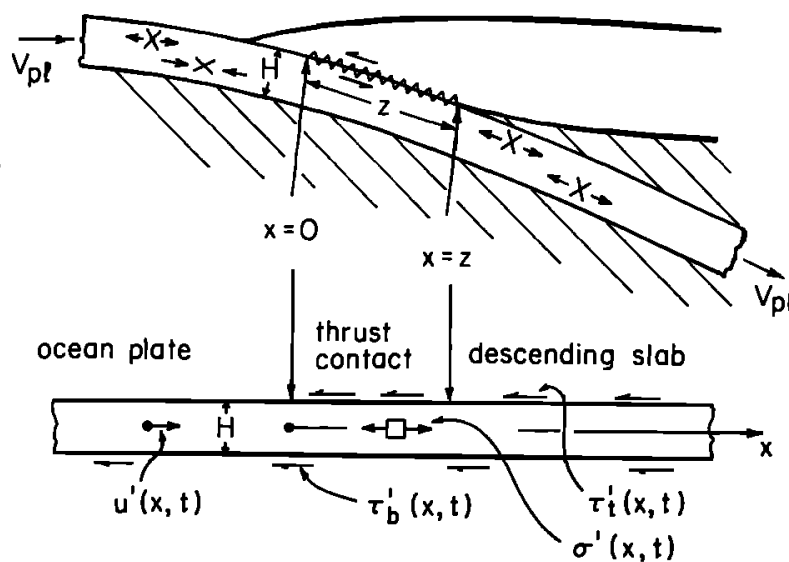

Fig. 11. (a) Subducting oceanic lithosphere, descending at average velocity $V_{p l^{\circ}}(b)$ One-dimensional model for perturbative stressing of plate due to intermittent slip along thrust contact zone.

$\dot{u}_{i}$ at position $\mathbf{r}(=x, y, z)$ in space, near the subduction zone, and at time $t$ may be given the representations

$$
\sigma_{i j}=\sigma_{i j}{ }^{\prime \prime}(\mathbf{r})+\sigma_{i j}{ }^{\prime}(\mathbf{r}, t) \quad \dot{u}_{i}=\dot{u}_{i}^{\prime \prime}(\mathbf{r})+\dot{u}_{i}^{\prime}(\mathbf{r}, t)
$$

Here the fields $\sigma_{i j}{ }^{\prime \prime}(\mathbf{r}), \dot{u}_{i}{ }^{\prime \prime}(\mathbf{r})$ denote an imagined steady subducting state with the following characteristics:

1. The fields are driven by body forces from density mismatch (slab pull, ridge push).

2. The forces are opposed by long-term viscous flow resistance in the asthenosphere below the underthrusting plate and in the wedge between it and the overriding plate and by slow bending resistance of the underthrusting plate.

3. The slip rate $\Delta^{\prime \prime}$ along the thrust contact zone is imposed, artificially, as being uniform in time, with $\Delta^{\prime \prime}=V_{p l} t$.

The steady state may be regarded as representing an average of the displacement rates over many earthquake cycles, and the magnitudes of $\dot{u}_{i}^{\prime \prime}(\mathbf{r})$ along the face of the slab are compatible with $V_{p l}$.

Hence the fields $\sigma_{i j}{ }^{\prime}(\mathbf{r}, t), \dot{u}_{i}^{\prime}(\mathbf{r}, t)$ are to be regarded as perturbations from the steady state just described, due to the irregular slippage in the thrust zone. Their characteristics are as follows:

1. They are driven by the difference slip function, $\Delta^{\prime}(x$, $t) \equiv \Delta(x, t)-V_{p l} t$, along the thrust contact zone (where $x$ is the position coordinate along that zone and $\Delta(x, t)$ is the total slip function there).

2. The stresses $\sigma_{i j}{ }^{\prime}$ equilibrate zero body forces, since the $\sigma_{i j}{ }^{\prime \prime}$ already equilibrate the gravitational forcing.

3. There is viscoelastic (rather than steady viscous) resistance of the asthenosphere beneath the underthrusting plate and in the wedge between it and the overriding plate, since now the stresses and strain rates vary in time. The subducting and overriding plates respond elastically.

The viscoelastic response to the perturbative fields should be described, strictly, as the response to a time-dependent perturbation from the steady strain rate field associated with $\dot{u}_{i}{ }^{\prime \prime}(\mathbf{r})$. If that viscoelastic perturbative response is approximated as being described, as here, by linear constitutive relations, then the $\sigma_{i j}{ }^{\prime}(\mathbf{r}, t)$ as well as the $\dot{u}_{i}^{\prime}(\mathbf{r}, t)$ have zero time average.

In the present work we address the perturbation fields. This is done in the context of a highly simplified one-dimensional model of the underthrusting plate, as in Figure $11 b$, for which only extensional and compressional deformation pertur- bations are considered, and simple Elsasser representations of the viscoelastic shear coupling are adopted. While the results of such a model are perhaps as much qualitative as quantitative, the model does seem to incorporate the essential overall physics of stress guiding and interactions in the subduction environment. The model has the virtue of simplicity and is tractable in a form which allows study of rather complex stress transfers and interactions.

The equations defining the model are as follows. Equilibrium requires that

$$
H \partial \sigma^{\prime}(x, t) / \partial x=\tau_{r}^{\prime}(x, t)+\tau_{b}{ }^{\prime}(x, t)
$$

Here $x$ is the coordinate running along the plate, $\sigma^{\prime}$ is the thickness average of local extensional stresses of type $\sigma_{x x}{ }^{\prime}$, and $\tau_{t}^{\prime}$ and $\tau_{b}{ }^{\prime}$ are the resistive shear stresses (Figure $11 b$ ) acting, respectively, on the top and bottom surface of the plate. The plate is assumed to extend elastically, under plane strain conditions, so that

$$
\sigma^{\prime}(x, t)=[2 \mu /(1-v)] \partial u^{\prime}(x, t) / \partial x
$$

where $u^{\prime}$ is the thickness average of local displacements of type $u_{x}{ }^{\prime}, \mu$ is the shear modulus, and $v$ is the Poisson ratio.

The region $-\infty<x<0$ is referred to as the ocean plate, $0<x<z$ as the thrust contact zone (later we take $z$ equal to $3 H$ ), and $z<x<\infty$ as the descending slab. Shear resistance $\tau_{t}^{\prime}$ is equal to 0 along the ocean plate, whereas $\tau_{t}^{\prime}$ along the descending slab $(z<x<\infty)$ and $\tau_{b}{ }^{\prime}$ everywhere $(-\infty<x<$ $+\infty$ ) are assumed to follow the Maxwellian viscoelastic coupling

$$
\partial u^{\prime}(x, t) / \partial t=(b / \mu)\left[\partial \tau^{\prime}(x, t) / \partial t+\left(1 / t_{r}\right) \tau^{\prime}(x, t)\right]
$$

where $\tau^{\prime}$ stands for $\tau_{b}{ }^{\prime}$ on $-\infty<x<+\infty$ or for $\tau_{t}^{\prime}$ on $z<$ $x<\infty$. This is a generalized Elsasser approximation to the coupling, as in previous work by Rice [1980], Lehner et al. [1981], Lehner and Li [1982], and Li and Rice [1983, 1987]. The relaxation time for the shear coupling is $t_{r}$, and $b$ is an effective scale length of the coupling deformation. The primary features of this description are that sudden plate displacements $u^{\prime}$ are resisted elastically by suddenly developed shear stresses $\tau^{\prime}=\mu u^{\prime} / b$ and that in the absence of ongoing displacement the resistive shear stresses simply relax in time, in Maxwell form. The corresponding relation adopted along the thrust contact zone, $0<x<z$, incorporates the same type of elastic response to sudden plate displacement $u^{\prime}$ in the absence of slip there but in the presence of slip $\Delta^{\prime}(x, t)\left(=\Delta(x, t)-V_{p l} t\right)$ along the thrust contact makes the response there proportional to $u^{\prime}-\Delta^{\prime}$. Thus

$$
\tau_{i}^{\prime}(x, t)=\mu\left[u^{\prime}(x, t)-\Delta^{\prime}(x, t)\right] / b
$$

on $0<x<z$.

Mechanically, equations (4) and (5) correspond to approximating the surroundings of the plate as a continuously distributed array of elastic spring elements and inelastic elements arranged in series. The inelastic elements are of viscous type, displacing at rate $b \tau^{\prime} / \mu t_{r}$, in (4) and of simple frictional type with displacement $\Delta^{\prime}$ in (5). This approximation gives local relations between the displacement and stress variables, whereas the actual relation between them is nonlocal. For example, the resistive shear stresses $t^{\prime}(\bar{x}, \bar{t})$ should actually be regarded as functional of $u^{\prime}(x, t)$ and $\Delta^{\prime}(x, t)$ over all $x$ for which the latter are defined and, because of the viscoelastic nature of response, over all $t \leq \bar{t}$. We discuss in Appendix A how to choose the parameter $b$. It is suggested there that a 
suitable choice, in order to have an approximately correct relation between sudden stress drop and average slip along the thrust contact, is that $b=2.3 \mathrm{H}$ when $z=3 \mathrm{H}$.

The specification of $\Delta(x, t)$, with rate averaging over time to $V_{p l}$ at each $x$, generates by the above system of equations (2) (5) histories of extensional stress perturbations $\sigma^{\prime}(x, t)$ along the plate and shear stress perturbations $\tau_{t}^{\prime}(x, t)$ along the thrust zone that we plot in the representative cases to follow.

It is important to recognize that those plots of $\sigma^{\prime}$ and $\tau_{f}^{\prime}$ represent only the cyclic (perturbative) parts of the stresses. Each averages in time to zero because of the linear perturbative constitutive description adopted. Hence comparison of stresses as plotted at different locations $x$ should not be used to draw inferences on differences of absolute stress levels at those locations. The magnitudes and spatial distributions of the stresses $\sigma^{\prime \prime}$ and $\tau_{t}^{\prime \prime}$ of the steadily subducting state, which may also be interpreted as the time averages of stresses over several earthquake cycles, have not been determined here. Consideration of the gravitational loading of subducting plates, as reviewed recently by Spence [1987], does, however, allow some characterization of these time average stresses. For example, the presumed dominance of slab pull as a driving force suggests that $\sigma^{\prime \prime}$ will correspond to extensional stresses in regions of the plate downdip from the thrust contact zone, that is, in the subducting slab zone of Figure 11. Also, since flexure of the plate is significant updip from the thrust contact toward the outer rise, we may expect $\sigma^{\prime \prime}$ to have a strong bending component there, that is, to be extensional at shallow depth and compressional at greater depth in the plate.

We wish to use our stress calculations to draw inferences on the induction of moderate seismicity, as documented in the earlier discussion. While the connections between stressing and seismicity are not clear in detail, the following hypothesis seems justified: Seismicity is induced when stresses are large and increasing. Here, by "large" in a seismically active zone undergoing earthquake cycles we mean of a magnitude approximately comparable to the largest stresses of the same type that occurred in previous cycles. The attribute "increasing" is necessary in the sense that reduction of stress will shut off seismicity (although a large enough reduction could induce seismicity of a different mode, e.g., with reverse slip).

\subsection{Results for Simple Thrust Earthquake Cycles}

In the first case we assume that $\Delta(x, t)$ jumps by $V_{p l} T$ everywhere along the thrust contact zone after each lapse of earthquake cycle time $T$ but remains constant in the interseismic period (Figure 12). Shortly, more elaborate spatially nonuniform slip histories $\Delta(x, t)$ will be considered which are still consistent with periodic earthquake cycles. In those, $\Delta$ has net increase $V_{p l} T$ at each location $x$ after a lapse of cycle time $T$ but has different detailed time histories by which that common increase accumulates at different locations $x$ along the thrust contact zone.

The method of solution begins with expanding $\Delta^{\prime}(x, t)$ in a Fourier series for the sawtooth difference function, $\Delta-V_{p l} t$, of Figure 12. Thus

$$
\Delta^{\prime}(x, t)=\left(\frac{V_{p l} T}{\pi}\right) \operatorname{Re}\left[\sum_{n=1}^{\infty}\left(\frac{1}{i n}\right) e^{2 \pi i n t / T}\right] \quad 0<x<z
$$

Here Re denotes "real part." Thus the approach is to generate solutions of type $f^{\prime}(x, t)=f^{\prime}(x) e^{i \lambda t}$ for all variables of the
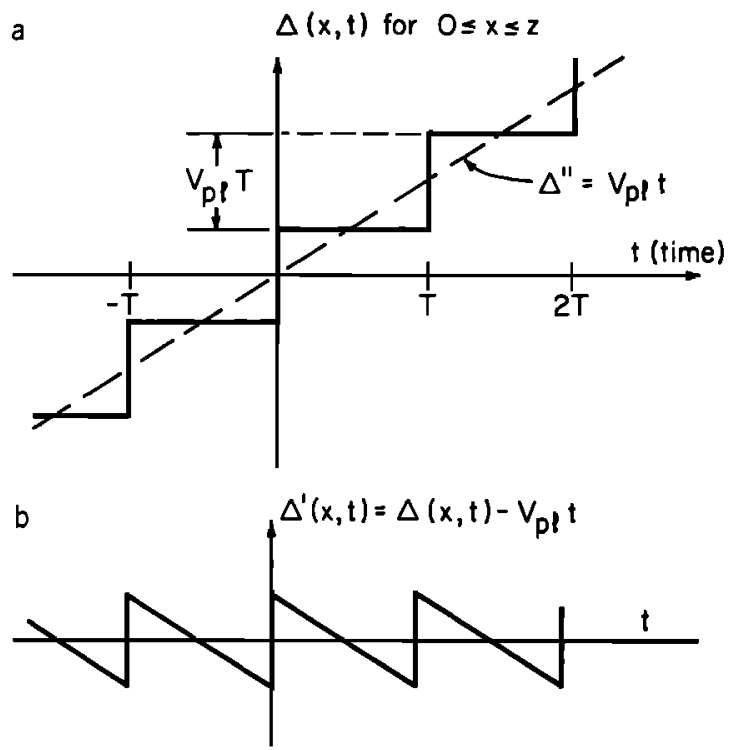

Fig. 12. (a) The slip history $\Delta$ along the thrust contact zone, with average time rate equal to $V_{p l}$, which describes periodic events with recurrence time $T$. (b) The slip history $\Delta^{\prime}$, which drives the perturbative fields and hence controls the time variation of stress.

problem $\left(u^{\prime}, \sigma^{\prime}, \tau_{t}^{\prime}, \tau_{b}^{\prime}\right)$ in response to $\Delta^{\prime}(x, t)=\Delta^{\prime}(x) e^{i \lambda t}$ and to superpose these according to the above series for $\Delta^{\prime}(x, t)$. Details are given in Appendix B.

Given the dimensionless manner in which the results are plotted in the following figures, the solutions depend on only two parameters. These are $z / H$ and $t_{r} / T$. We show results in Figures $13-15$ for a case in which the thrust contact zone width $z$ is equal to $3 H(H=30 \mathrm{~km}$ would be representative for the Middle American Trench off Mexico) and the relaxation time $t_{r}$ is equal to $0.14 T$ (e.g., $t_{r}=5-10$ years if $T=35-70$ years).

Figure 13 shows the shear stress $\tau_{t}^{\prime}$ throughout the cycle at two locations along the thrust contact zone, one toward the lower border at $x=2.9 \mathrm{H}$ and the other toward the middle at $x=1.6 H$. Each stress shown here and subsequently is strictly

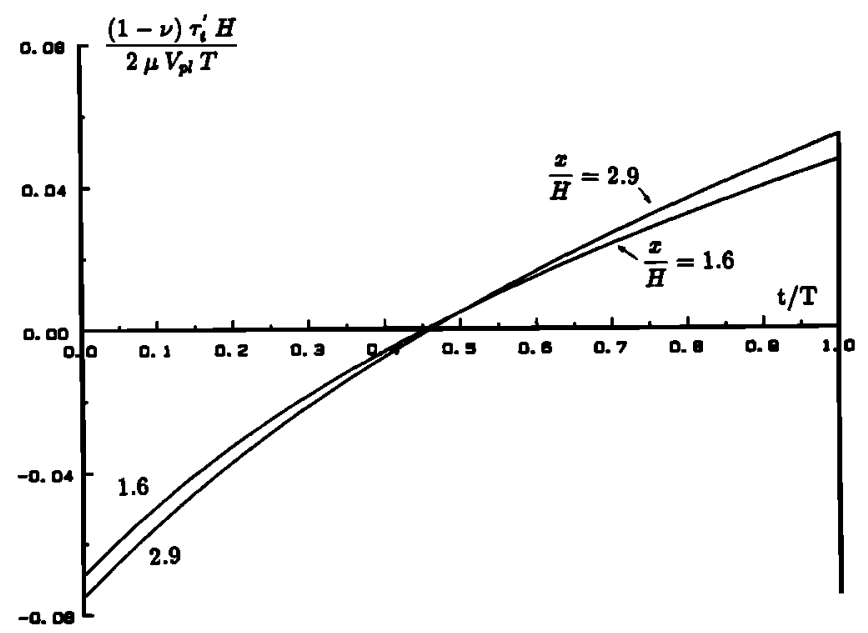

Fig. 13. Shear stress perturbation $\tau_{i}^{\prime}$ along the thrust contact zone, due to periodic events of Figure 12. The zone extends from $x=0$ to $x=3 H$, and $t_{r}=0.14 T$. The history of this and all other stresses shown subsequently for $0<t / T<1$ repeats periodically on $1<t / T<2,2<t / T<3$, etc 


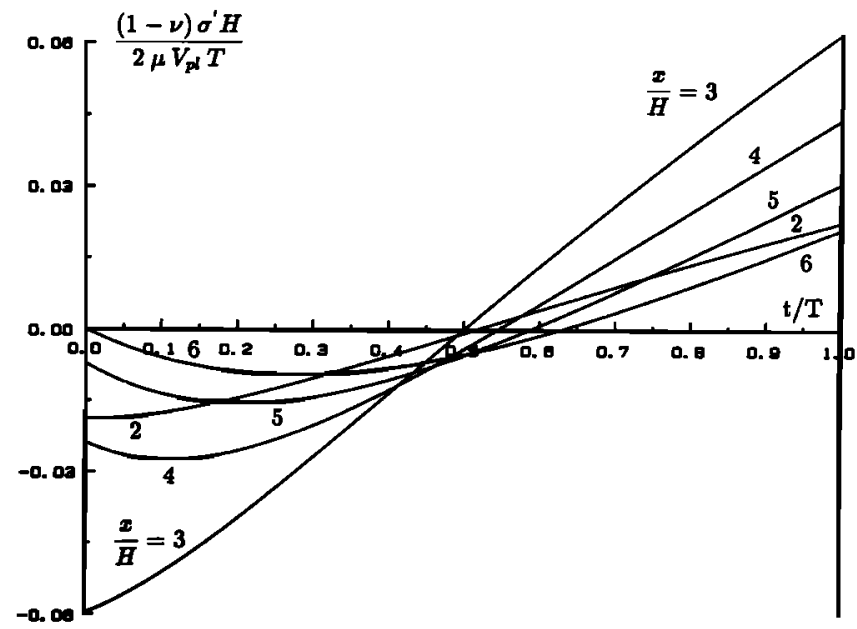

Fig. 14. Extensional stress perturbation $\sigma^{\prime}$ in the subducting slab downdip from the thrust contact at $x=3 H, 4 H, 5 H$, and $6 H$, and at location $x=2 H$ beneath the thrust contact.

periodic so that the history shown on $0 \leq t / T \leq 1$ repeats on $1 \leq t / T \leq 2$, etc. The stress accumulation is nonlinear in time with half the earthquake stress drop being regained in the first $37 \%$ of the cycle. Of course, the stress histories are consistent with a relative absence of thrust seismicity in the earlier portions of the cycle by comparison to later portions when high shear stresses have been recovered. The simple model is not able to deal realistically with the inevitable stress concentration at the lower portion of the thrust contact zone $\left(\tau_{t}^{\prime}\right.$ would have a crack-tip-like singularity at $x=3 H$ in an exact analysis based on the boundary conditions imposed here).

Figure 14 shows the extensional stress $\sigma^{\prime}$ in the descending slab at locations downdip from the thrust contact between $x=3 H$ and $x=6 H$ and also at a location beneath the thrust contact at $x=2 H$. The most severe variations in stress occur, as expected, at the downdip edge of the thrust contact zone at $x=3 H$, and the stress variations attenuate with distance downdip in the slab.

To interpret these results in terms of seismicity, recall that total stress $\sigma$ is equal to $\sigma^{\prime \prime}+\sigma^{\prime}$ and that because of the dominance of slab pull in driving the subduction process the timeindependent mean stress $\sigma$ " will be of extensional character in the part of the descending slab considered. Thus one expects the total stress $\sigma$ to be extensional at all times. Not only is the magnitude of $\sigma$ reduced by the great earthquake, but as shown by the curves for $x=4 H, 5 H$, and $6 H$ in Figure 14, $\sigma$ within the descending slab continues to reduce for $15-30 \%$ of the next earthquake cycle. These results are consistent with the relative absence of extensional seismicity in the slab during the first hall or so of the cycle, as noted earlier, whereas the increases of $\sigma$ in the latter part of the cycle are consistent with the reactivation at that time of extensional normal faulting.

Figure 15 shows the extensional stress $\sigma^{\prime}$ updip from the thrust contact in a region of ocean plate extending from the trench (approximately at $x=0$ ) over negative values of $x$ toward the outer rise. The time-independent mean stress $\sigma^{\prime \prime}$ should correspond to a bending distribution in the vicinity of the outer rise, which is extensional at shallow depths and compressional at greater depths in the plate, and the timedependent extensional stress $\sigma^{\prime}$ shown is added to it to form the total stress $\sigma=\sigma^{\prime \prime}+\sigma^{\prime}$.

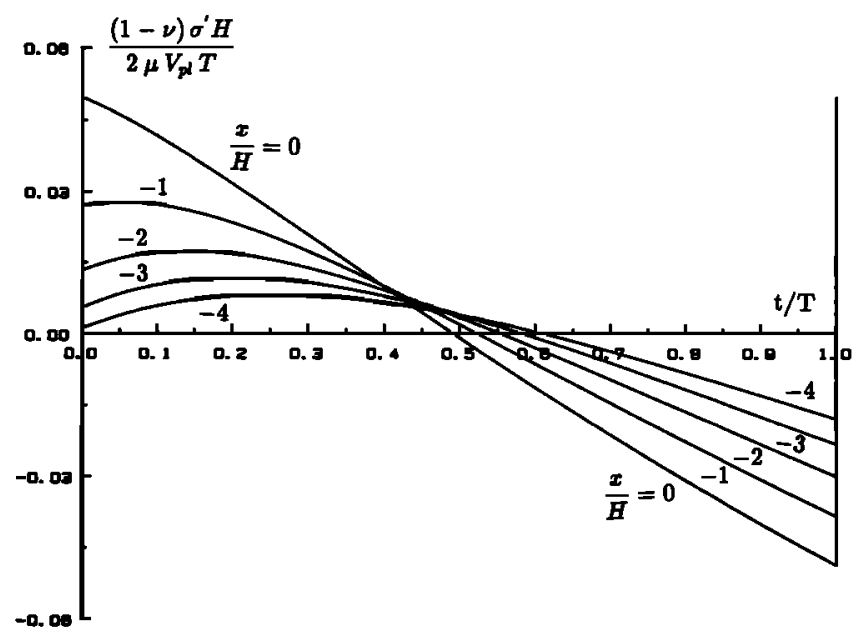

Fig. 15. Extensional stress perturbation $\sigma^{\prime}$ updip from thrust contact, toward the outer rise, shown at $x=0,-H,-2 H,-3 H$, and $-4 H$.

Thus in the early portion of the cycle when $\sigma^{\prime}$ is positive the eflect is to produce large shallow extensional $\sigma$ but to diminish the compressional $\sigma$ at greater depths in the plate. Similarly, in the later portions of the cycle when $\sigma^{\prime}$ begins to diminish and become negative the effect is to produce large compressional $\sigma$ at depth but to diminish the extensional $\sigma$ in the shallower parts of the plate. The first feature is consistent with the observed extensional seismicity toward the outer rise discussed previously, in the early part of the earthquake cycle. As the curves for $x=-H$ to $-4 H$ in Figure 15 show, the stress $\sigma$ motıvating such seismicity continues to increase for up to

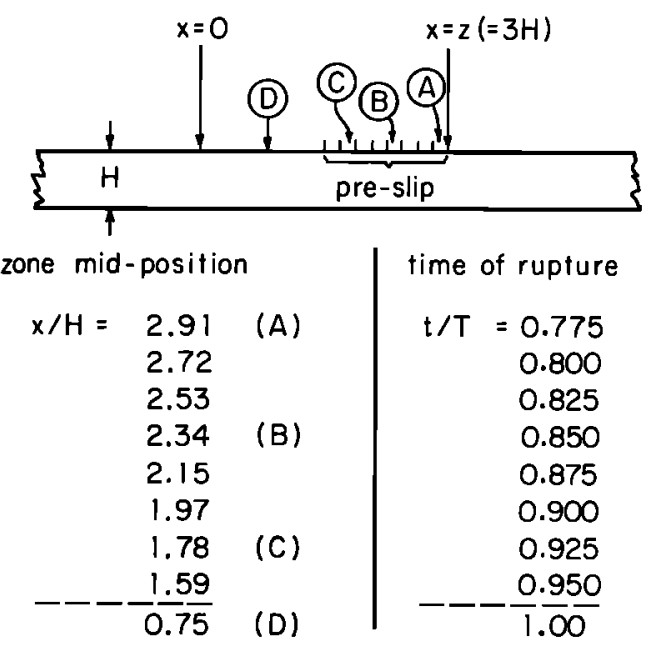

Fig. 16. The thrust contact zone divided into two parts, one (with $1.5 H<x<3 H$ ) which preslips and partially drops its stress before completion of cycle of duration $T$, and another (with $0<x<1.5 \mathrm{H}$ ) which remains locked and slips only during the main event, by amount $V_{p t} T$. The preslip zone also slips during the main event, to make up the deficit between $V_{p l} T$ and preslip. For numerical purposes, the preslip zone is divided into eight sectors which move only at discrete times, spaced by $T / 40=0.025 T$. Preslip is represented as an episode in which the slip zone starts at the lowest point of the thrust contact at $x=3 H$ and propagates upward to $x=1.5 H$ at a uniform rate over time interval $0.2 T$. Once a sector is traversed by the slip zone, i.e., once "ruptured," it slips for all subsequent time in the cycle to maintain fixed stress drop $\Delta \tau$. Sector-by-sector advance of the slip zone is indicated in the lower part of the figure. 
$30 \%$ of the next cycle, suggesting a prolonged period of extensional seismicity. The later changes toward compressive $\sigma$ as the cycle goes on are consistent with an absence of extensional seismicity toward the outer rise in the later portions of the cycle but with occasional compressive (or thrust) seismicity in that region of the ocean plate, as observed in cases noted earlier.

The shapes of the curves in Figures 14 and 15 reflect a competition between stress diffusion from the unloading event along the thrust zone and continued loading from the ongoing subduction process. The former is important in the earlier portions of the cycle and dominates the shape of the curves there, producing the local extrema in $\sigma$. It is a negligible effect in the later portions of the cycle where stress accumulation is dominated by the ongoing loading process.

\subsection{Interactions Between Preslip in the Thrust Contact \\ Zone and Slab Stressing}

The previous discussion of seismicity noted regions along the Middle American Trench where the lower portions of the thrust contact zone undergo periods of active seismicity, especially during the latter half or so of the cycle. In some cases

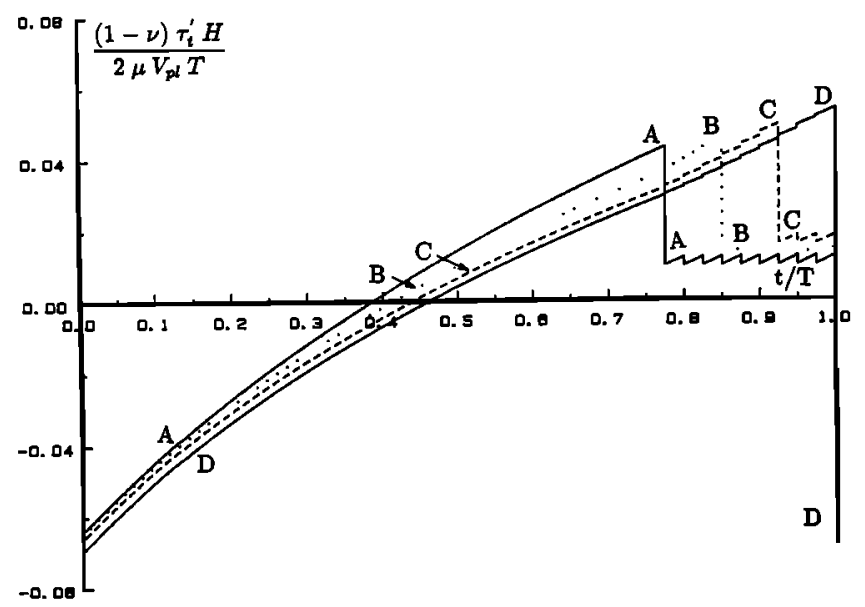

Fig. $17 a$

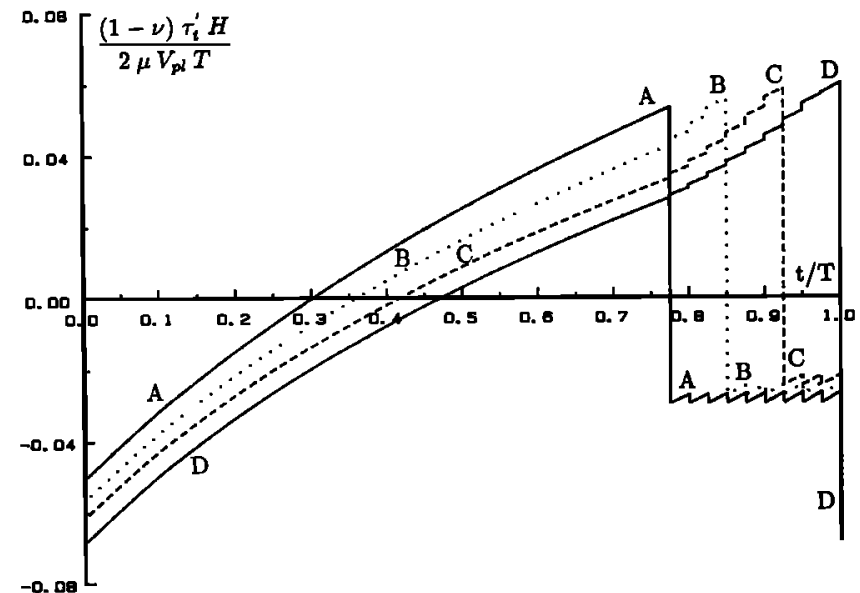

Fig. $17 b$

Fig. 17. Shear stress perturbation $\tau_{i}^{\prime}$ at various points along thrust contact zone for $(a)$ small stress drop $\Delta \tau$ and $(b)$ large $\Delta \tau$. Refer to Figure 16 for locations of points labeled A, B, C (in preslip zone), and $\mathrm{D}$ (main rupture zone).

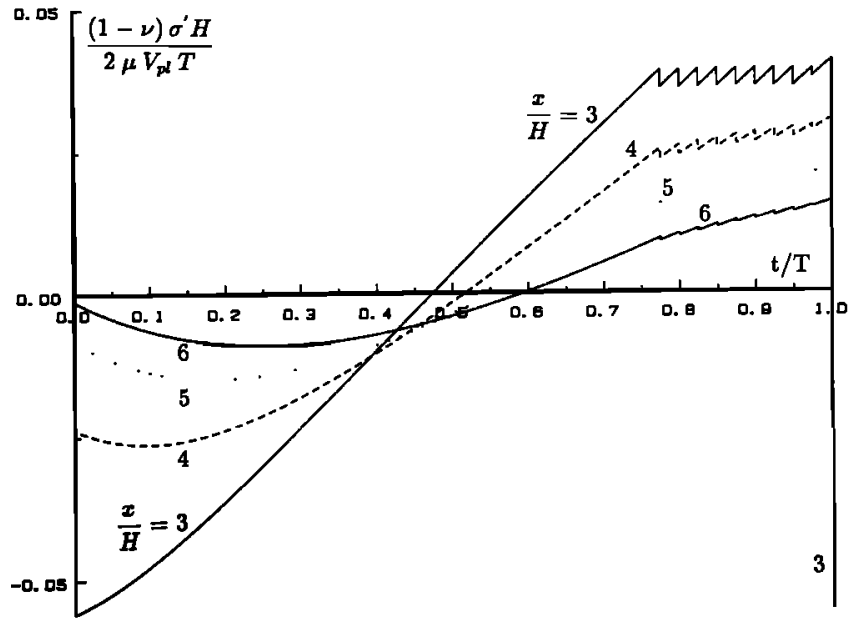

Fig. $18 a$

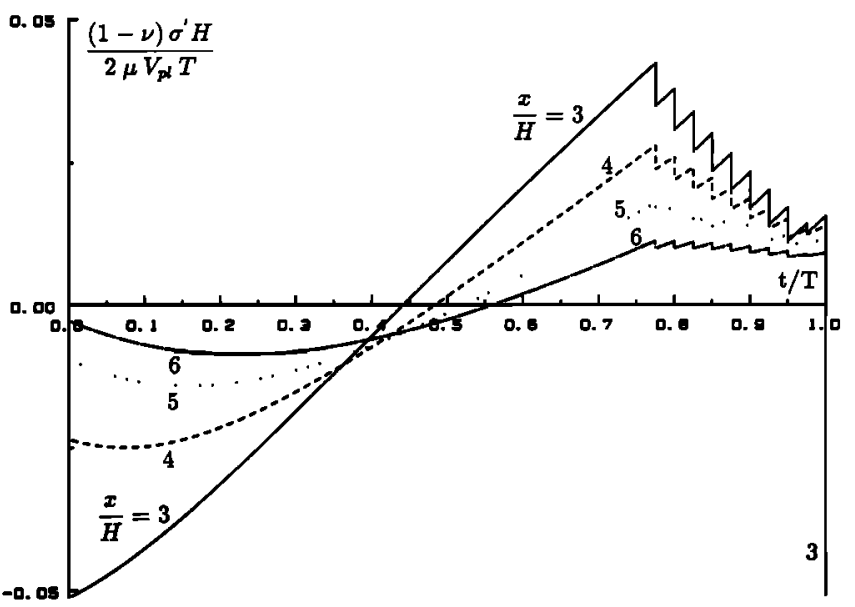

Fig. $18 b$

Fig. 18. Extensional stress perturbation $\sigma^{\prime}$ downdip from thrust contact at $x=3 H, 4 H, 5 H$, and $6 H$ for $(a)$ small $\Delta \tau$ and $(b)$ large $\Delta \tau$.

these periods of activity appeared to precede temporary quiescence of extensional seismicity downdip in the slab. It seems plausible that seismicity of thrust type in the lower, and hence hotter, regions of the thrust contact zone could be a sign of a partially aseismic preslip taking place there well prior to slip in the great earthquake. Such preslip below a cooler, more firmly locked fault zone occurs in the Tse and Rice [1986] simulations of slip development throughout the strike slip earthquake cycle based on frictional constitutive relations dependent on slip rate, history, and temperature.

Here we report model calculations based on the same parameters as before but with the assumption that the lower half of the thrust contact zone between $x=1.5 H$ and $x=3 H$ undergoes preslip. As suggested by Figure 16, we represent the preslip as an episode in which a slip zone starts at the lowest portion of the thrust contact zone, at $x=3 H$, and extends at a uniform rate up to $x=1.5 H$ over a time interval $\Delta t=T / 5$. For computational purposes the preslip region is subdivided into eight equal zones, broken consecutively by the propagating slip event with time interval $T / 40$ between successive breaks. Breaking is taken to mean that the shear stress $\tau_{\mathrm{t}}$ is suddenly reduced by some fixed stress drop $\Delta \tau$. In these calcu- 


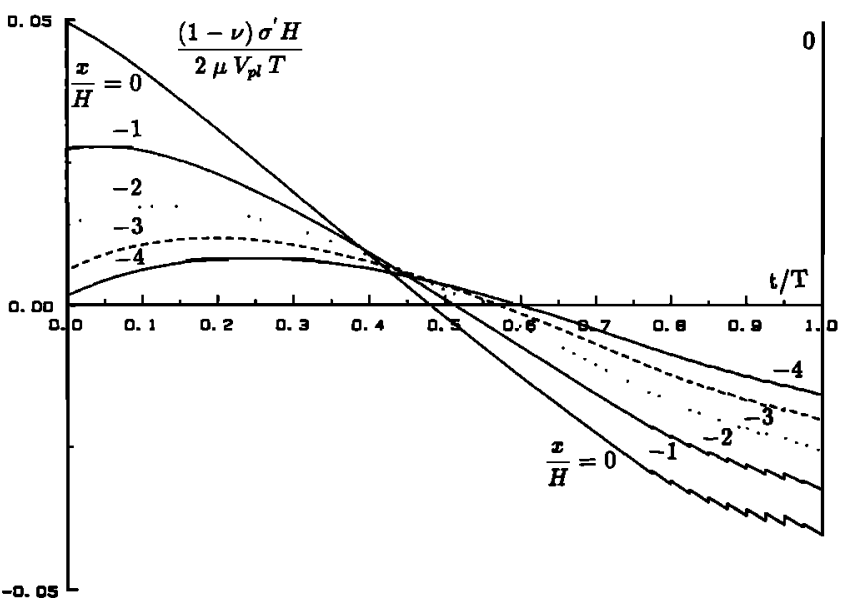

Fig. $19 a$

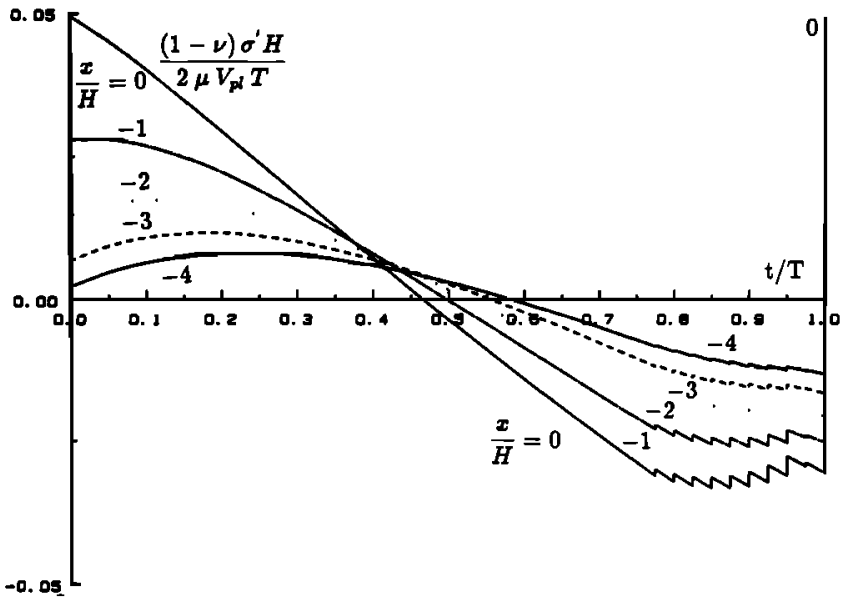

Fig. $19 b$

Fig. 19. Extensional stress perturbation $\sigma^{\prime}$ updip, toward outer rise, at $x=0,-H,-2 H,-3 H$, and $-4 H$ for $(a)$ small $\Delta \tau$ and $(b)$ large $\Delta \tau$.

lations we assume that once a zone breaks, it stays broken such that the stress $\tau_{t}$ there remains at the reduced level for the remainder of the cycle. As part of what then turns out to be a rather elaborate calculation (Appendix B gives details), we calculate the slip history $\Delta(x, t)$ at each broken segment which is necessary to keep $\tau_{t}$ reduced there. However, to save computing and programming time, we readjust the stresses back down to their proper level only after each time interval $T / 40$ so that the preslip accumulates in eight steps over $20 \%$ of the cycle, rather than continuously.

Figure 17 shows the results for $\tau_{t}$ at the three locations (A, $B$, and $C$ ) of Figure 16 through which the preslip propagates and at location $\mathrm{D}$ at the center of the remaining part of the thrust contact that ruptures only during the great earthquake at $t=T$. Figures $17 a$ and $17 b$ represent the respective cases of modest and large stress drop $\Delta \tau$ in the preslip. Figures 18-20 are divided similarly. In the large $\Delta \tau$ case the stress $\tau_{t}$ during the preslip is reduced by $75 \%$ of its total reduction to the level just after the great earthquake (at $t=T^{+}$, corresponding also to $t=0^{+}$in the periodic model).

Figure 18 shows histories of extensional stress $\sigma^{\prime}$ at locations along the descending slab downdip from the bottom of the thrust contact $(x \geq 3 H)$. Figure 19 shows $\sigma^{\prime}$ at various locations $x$ updip in the slab and along the ocean plate (negative $x$ values) toward the outer rise. Figure 20 shows $\sigma^{\prime}$ at $x=2 H$, a location traversed by the preslip episode, which thereby creates a large transient stress pulse there.

We note from Figure 18 that preslip episodes like those considered can appreciably reduce the rate of growth of extensional stress in the descending slab and, if large enough, can even transiently reverse the late-cycle buildup of extensional stress there. Figure 19 shows similar but more modest effects on compressional stress updip in the plate. These transient unloading effects within the subducting plate occur while the still locked thrust zone segment ( $D$ of Figure 16) continues to experience an every rising shear stress, as seen in Figure 17.

The scenario just described provides a possible mechanism for seismic quiescence before great subduction zone earthquakes. What seems to be required is a preslip episode, which significantly drops shear stress in the slipped region, over a relatively short fraction of the whole cycle time, but whose continued propagation undip in the thrust zone (and hence, one assumes, continued generation of thrust zone seismicity) is blocked by encounter with a strong asperity. The interactive reductions of downdip extension and updip compression in

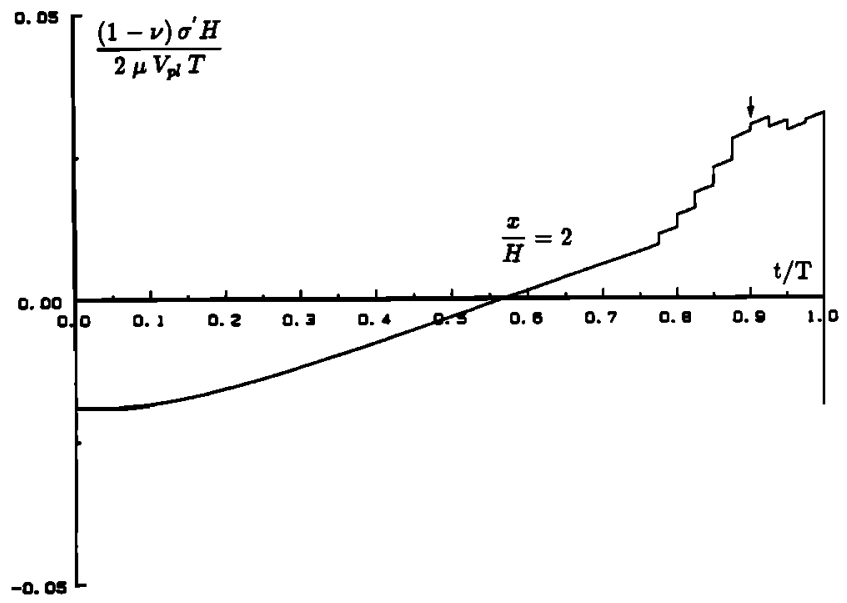

Fig. $20 a$

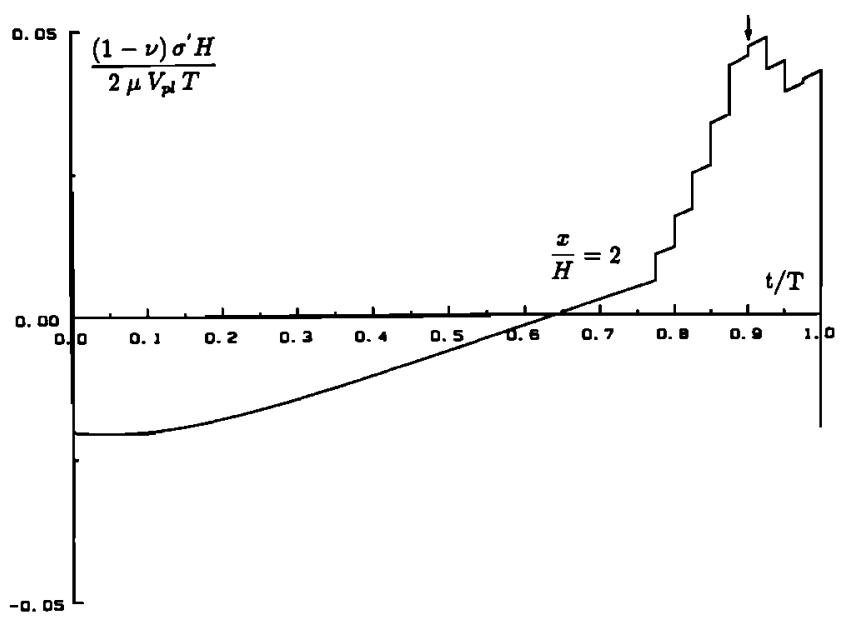

Fig. $20 b$

Fig. 20. Extensional stress perturbation $\sigma^{\prime}$ at location $x=2 H$, beneath preslip zone (and traversed by propagating slip front at the time indicated by the arrow), for (a) small $\Delta \tau$ and (b) large $\Delta \tau$. 
the plate, described above, stop the seismicity from those regions too. The blocking asperity may, in fact, simply be a zone of cooler (shallower) and hence stronger but more brittle material, whose eventual penetration by accumulating shear stress triggers the final instability.

Similar mechanisms provide a possible basis for interlaced periods of seismicity and quiescence, as we have shown for some regions along the Middle American Trench. Developments of large extensional stresses from slab pull transfers shear stress to the thrust contact zone. A preslip episode induced by these stresses could transiently unload the extensional stress in the descending slab through the mechanism described above but could ultimately become blocked by encounter of the advancing slip front with strong asperities. Ultimately, the ongoing loading effects redevelop extensional stresses in the slab, and these transfer yet greater shear stresses to the thrust contact, enabling more advance of the preslip zone there as it penetrates some of the blocking asperities, but possibly also producing yet another transient unloading in the descending slab. A plausible pattern of seismicity to go with this conjectured scenario is as follows: extensional seismicity in the descending slab (signifying the high stresses), initiation of thrust zone seismicity (start of preslip episode) with induced quiescence in the slab, quiescence in the thrust zone (blockage by asperities), reactivation of the slab (ongoing loading), and reinitiation of thrust zone seismicity (penetration of blocking asperities) with possible reinduction of quiescence in the slab.

The results of Figure 20 show that an advancing slip front induced significant extensional stress in the slab below. Although we do not address it here, there would also be compressional stresses induced similarly in the overriding plate. Some of the seismicity induced by slip advance in a thrust zone may be from these adjoining regions. The particular location $x=2 H$, at which $\sigma^{\prime}$ is shown in Figure 20, is traversed in the sixth (marked by arrow) of the eight steps of preslip advance in our model. After traversal the stress reduces modestly until the ongoing loading effects cause it to increase again.

\section{CONCLUSION}

The results of an elementary model of stress variation in time through the earthquake cycle for coupled subduction zones are compatible with seismicity observations from such zones around the world. In particular, model simulations are compatible with the presence of extensional outer-rise earthquakes early in the cycle and compressional ones later in the cycle and with extensional (normal) intraplate earthquakes, downdip from the zones of main subduction events, in the latter part of the cycle. Also, the model simulations of interactions between preslip in the thrust zone and stressing in the descending slab may successfully, though nonuniquely, explain some observed seismicity episodes and, also, precursory seismic quiescence.

According to the concepts introduced here, the combination of both moderate compressional events in the outer rise and normal (tensional) intraplate events in the descending slab provide mechanical signals that stresses in both those regions are attaining values comparable to the largest stresses sustained in previous earthquake cycles. Correspondingly, the high-compressional stress in the oceanic plate and tensional stress in the descending slab imply that the locked thrust zone, which impedes motion of the ocean plate into it and of the slab downdip, is subjected to high shear loading. Thus the occurrence of both types of events, as seen in Figure 1 before the Valparaiso earthquake of November 7, 1981, and in Figure 2 before the northern Chile earthquake of October 4, 1983 , looks very promising as an intermediate-term precursor to large subduction earthquakes. Further search of seismic catalogs has revealed other combinations of this type, some completed by large subduction events and some not yet completed [Dmowska and Lovison, 1988].

\section{Appendix A: Choice of Parameter $b$}

Working with the equations of the one-dimensional model described by equations (2), (3), and (4), suppose that the stress $\tau_{t}$ is suddenly dropped by the uniform amount $\tau$ along the thrust contact zone $0<x<z$. The surroundings respond elastically, and the sudden displacement $u$ in the plate is such that $B d^{2} u / d x^{2}$ must be equal to $u$ on $-\infty<x<0, u-b \tau / \mu$ on $0<x<z$, and $2 u$ on $z<x<\infty$. Here $B=2 b H /(1-v)$. The solution for $u$ is constructed by requiring that $u$ and $d u / d x$ be continuous. The resulting expression on $0<x<z$ is

$$
\begin{aligned}
u=\frac{b \tau}{2 \mu(1+\sqrt{2})}\left[2(1+\sqrt{2})-(1+\sqrt{2}) e^{-x / B^{1 / 2}}\right. \\
\left.-2 \sqrt{2} e^{-(z-x) / B^{1 / 2}}+(\sqrt{2}-1) e^{-(2 z-x) / B^{1 / 2}}\right]
\end{aligned}
$$

The corresponding sudden slip $\Delta$ along the thrust contact may be calculated from (5) as $u+b \tau / \mu$, and the average value $\bar{\Delta}$ of $\Delta$ over the zone $0 \leq x \leq z$ is

$$
\begin{aligned}
\bar{\Delta}=\frac{b \tau}{2 \mu z(1+\sqrt{2})}\left\{4 z(1+\sqrt{2})-B^{1 / 2}\left(1-e^{-z / B^{1 / 2}}\right)\right. \\
\left.\cdot\left[(1+3 \sqrt{2})-(\sqrt{2}-1) e^{-z / B^{1 / 2}}\right]\right\}
\end{aligned}
$$

In comparison, the average slip $\bar{\Delta}$ for a shear fault of width $z$, penetrating the boundary of an elastic half-space and sustaining a uniform stress drop $\tau$ under plane strain conditions, may be approximately estimated as that of a fault of width $2 z$ in an elastic full space with the same stress drop. This estimate is exact for antiplane (strike slip) faults, penetrating perpendicularly to the boundary of a half-space. It is not exact for plane strain (thrust) faults, as are of concern here, nor is it exact even for antiplane faults when the dip angle differs from $90^{\circ}$. Thus we write

$$
\bar{\Delta}=4(1-v) \tau z / \pi \zeta \mu
$$

where $\zeta=1$ would correspond to the fault of width $2 z$ in a full space. Dmowska and Kostrov [1973] developed and solved numerically an integral equation for the slip distribution on a dip slip fault with uniform stress drop. W. D. Stuart (private communication, 1986) has recently used a similar formulation and has kindly provided some estimates of $\zeta$ for faults dipping at $15^{\circ}$ into an elastic half-space with $v=0.25$. He obtains $\zeta=0.56$ for uniform $\tau$ on a fault of width $z$. When the total fault width is $z /(1-\alpha)$ and there is uniform $\tau$ over a deep segment of the fault of width $z$ but zero stress drop over the remaining shallow segment of width $\alpha z /(1-\alpha)$, he obtains $\zeta=0.64$ when $\alpha=0.2$ and $\zeta=0.70$ when $\alpha=0.4$. The latter estimates assume that the shallow segment (i.e., that between the trench and the upper edge of a great rupture zone) actually slips in the great event. When the shallow segment is locked against slip, $\zeta$ will be yet larger; its largest feasible value is $\zeta=2$, corresponding to $\alpha \rightarrow 1$, with no slip over any but the deep segment of width $z$ sustaining stress drop $\tau$ (this corresponds to the fault of width $z$ in a full space). 
We have done the calculations here for a value of $B$ such that (A2) and (A3) give identical results when $\zeta=0.9$. Equating the two determines $B^{1 / 2} / z$ as a function of $z / H$. When $z=3 H$, this gives $B \approx 6 H^{2}$ which, taking $v=0.25$, corresponds to $b \approx 2.3 H$.

\section{ApPendix B: Solution of Equations}

Let $u^{\prime}=u^{\prime}(x) e^{i \lambda t}$ be the response of equations (2), (3), (4), and (5) to $\Delta^{\prime}=\Delta^{\prime}(x) e^{i \lambda t}$, where $\Delta^{\prime}(x)$ is defined on $0 \leq x \leq z$ and, to fit the range of applications considered here, may be assumed to have the rectangular form

$$
\begin{array}{ll}
\Delta^{\prime}(x)=\Delta_{*}^{\prime} & \xi \leq x \leq \eta \\
\Delta^{\prime}(x)=0 & \text { otherwise }
\end{array}
$$

where $0 \leq \xi \leq \eta \leq z$ and $\Delta_{*}^{\prime}$ is constant. Then (2), (3), (4), and (5) require that

$$
d^{2} u^{\prime}(x) / d x^{2}=\alpha^{2}(x) u^{\prime}(x)-\Delta^{\prime}(x) / B
$$

where $B=2 b H /(1-v)$, one deletes the term $\Delta^{\prime}(x)$ outside $0 \leq x \leq z$, and $\alpha(x)$ has positive real part and has piecewise uniform values given by

$$
\begin{array}{cc}
\alpha^{2}(x)=\alpha_{0}{ }^{2} \equiv i \lambda t_{r} / B\left(1+i \lambda t_{r}\right) & -\infty<x<0 \\
\alpha^{2}(x)=\alpha_{r}^{2} \equiv\left(1+2 i \lambda t_{r}\right) / B\left(1+i \lambda t_{r}\right) & 0 \leq x \leq z \\
\alpha^{2}(x)=\alpha_{s}{ }^{2} \equiv 2 \alpha_{0}{ }^{2} \quad z<x<\infty
\end{array}
$$

Hence the solution in the various domains is

$$
\begin{gathered}
u^{\prime}(x)=A_{0} e^{\alpha_{0} x} \quad-\infty<x<0 \\
u^{\prime}(x)=A_{t} e^{\alpha_{t} x}+B_{t} e^{-\alpha_{t} x}+u_{p}^{\prime}(x) \quad 0 \leq x \leq z \\
u^{\prime}(x)=B_{s} e^{-\alpha_{s} x} \quad z<x<\infty
\end{gathered}
$$

where $u_{p}^{\prime}(x)$ is the particular solution of (B2) corresponding to (B1), that is,

$$
\begin{aligned}
u_{p}^{\prime}(x)=\left(\Delta_{*}{ }^{\prime} / 2 B \alpha_{t}{ }^{2}\right)\{\operatorname{sgn}( & x-\xi)\left[1-e^{-x_{t}|x-\xi|}\right] \\
& \left.-\operatorname{sgn}(x-\eta)\left[1-e^{-x_{t}|x-\eta|}\right]\right\}
\end{aligned}
$$

where sgn $(x)$ means "sign of $x$."

The constants $A_{0}, A_{t}, B_{t}$, and $B_{s}$ must be chosen to make $u^{\prime}(x)$ and $d u^{\prime}(x) / d x$ continuous at $x=0$ and $x=z$. They are thus expressed by

$$
\begin{aligned}
& A_{t}=\left(\alpha_{t}-\alpha_{s}\right)\left[\left(\alpha_{t}-\alpha_{0}\right) e^{-\alpha_{t} z} u_{p}^{\prime}(0)+\left(\alpha_{t}+\alpha_{0}\right) u_{p}^{\prime}(z)\right] / C \\
& B_{t}=\left(\alpha_{t}-\alpha_{0}\right)\left[\left(\alpha_{t}+\alpha_{s}\right) e^{\alpha_{t} z} u_{p}^{\prime}(0)+\left(\alpha_{t}-\alpha_{s}\right) u_{p}^{\prime}(z)\right] / C
\end{aligned}
$$

where

$$
\begin{gathered}
C=\left(\alpha_{t}+\alpha_{0}\right)\left(\alpha_{t}+\alpha_{s}\right) e^{\alpha_{t} z}-\left(\alpha_{t}-\alpha_{0}\right)\left(\alpha_{t}-\alpha_{s}\right) e^{-\alpha_{t} z} \\
A_{0}=\left[2 \alpha_{t} /\left(\alpha_{t}+\alpha_{0}\right)\right]\left[A_{t}+u_{p}^{\prime}(0)\right] \\
B_{s}=\left[2 \alpha_{t} e^{\alpha_{s} z} /\left(\alpha_{t}+\alpha_{s}\right)\right]\left[B_{t} e^{-\alpha_{t} z}+u_{p}^{\prime}(z)\right]
\end{gathered}
$$

Let the solution described for $u^{\prime}(x)$ in (B4)-(B8) be denoted henceforth as $\Delta_{*}^{\prime} U(x, \lambda ; \xi, \eta)$. Thus $u^{\prime}(x, t)=\Delta_{*}{ }^{\prime} U(x, \lambda ; \xi$, $\eta) e^{i \lambda t}$ is the displacement history in response to the slip history $\Delta^{\prime}(x, t)=\Delta_{*}^{\prime} e^{i \lambda t}$ on $\xi \leq x \leq \eta$ and $\Delta^{\prime}(x, t)=0$ otherwise.

The sawtooth $\Delta^{\prime}(x, t)$ history of Figure 12, which is uniform along $0 \leq x \leq z$, has the Fourier representation as in (6). Thus the solution in response to that sawtooth history is

$u^{\prime}(x, t)=\left(\frac{V_{p l} T}{\pi}\right) \operatorname{Re}\left[\sum_{n=1}^{\infty}\left(\frac{1}{i n}\right) U\left(x, \frac{2 n \pi}{T} ; 0, z\right) e^{2 i \pi n t / T}\right]$

and this solution, when used in (3) and (5), is the basis for the plots of $\tau_{t}^{\prime}(x, t)$ and $\sigma^{\prime}(x, t)$ shown in Figures 13-15. To speed convergence, we extract the part of the series behaving as $1 / n$ to write

$$
\begin{aligned}
u^{\prime}(x, t)= & V_{p t} T\left\{U(x, \infty ; 0, z) S(t)+\operatorname{Re} \sum_{n=1}^{\infty}\left(\frac{1}{i \pi n}\right)\right. \\
\cdot & {\left.\left[U\left(x, \frac{2 n \pi}{T} ; 0, z\right)-U(x, \infty ; 0, z)\right] e^{2 i \pi n t / T}\right\} }
\end{aligned}
$$

where $S(t)$ is the unit sawtooth of period $T$, as in Figure $12 b$ but with amplitude equal to $\frac{1}{2}$, that is, discontinuous jump of unity.

To describe periodic earthquake cycles with preslip in the thrust contact zone, $0 \leq x \leq z$, we divide that region into segments. Slip $\Delta(x, t)$ is assumed to be spatially uniform in each such segment. For example, Figure 16 shows a nine-segment division of the thrust zone, of which the eight small segments over $z / 2 \leq x \leq z$ describe the preslip zone and the large segment over $0 \leq x \leq z / 2$ describes the part which slips in the great event. Let $k=0$ index the latter segment and $k=1-8$ the smaller segments. A segment is allowed to slip only at a discrete time $t_{j}=j T / 40$ when the cycle is broken into 40 steps as in our Figures 17-20, where $j=0,1,2, \cdots, 39$. Time $t_{0}$ corresponds to the large earthquake (and thus is equivalent to $\left.t_{40}\right)$. Let $\Delta_{k j}$ be the slip step in segment $k$ at time $t_{j}$. Evidently,

$$
\Delta_{00}=V_{p l} T \quad \Delta_{k 0}=V_{p l} T-\sum_{j=1}^{39} \Delta_{k j} \quad k \geq 1
$$

since each zone slips by $V_{p l} T$ in a cycle. Note that $\Delta_{0 j}=0$ for $j \geq 1$ and that $\Delta_{k j}$ for $k=1-8$ and $j=1-39$ describes the preslip history. Once we convert $\Delta$ to $\Delta^{\prime}$, we may calculate $u^{\prime}(x, t)$ as the sum of response to $9 \times 40$ slip histories of type

$$
\begin{array}{ll}
\Delta^{\prime}(x, t)=\Delta_{k j} S\left(t-t_{j}\right) & \xi_{k}<x<\eta_{k} \\
\Delta^{\prime}(x, t)=0 & \text { otherwise }
\end{array}
$$

where $\xi_{k}<x<\eta_{k}$ gives the range of segment $k$. Thus the solution for $u^{\prime}(x, t)$, in response to a history that includes preslip and is repeated periodically, is

$$
\begin{array}{r}
u^{\prime}(x, t)=\sum_{k=0}^{8} \sum_{j=0}^{39}\left\{( \frac { \Delta _ { k j } } { \pi } ) \operatorname { R e } \left[\sum_{n=1}^{\infty}\left(\frac{1}{i n}\right)\right.\right. \\
\left.\left.\cdot U\left(x, \frac{2 n \pi}{T} ; \xi_{k}, \eta_{k}\right) e^{2 i \pi n(t-t j) / T}\right]\right\}
\end{array}
$$

(in practice the infinite sums are rearranged as in (B10) above). This solution is used with (4) to calculate $\tau_{t}^{\prime}(x, t)$ along the thrust contact as

$$
\tau_{t}^{\prime}(x, t)=\sum_{k=0}^{8} \sum_{j=0}^{39} \Delta_{k j} F_{k}\left(x, t-t_{j}\right)
$$

where

$$
\begin{gathered}
F_{k}(x, t)=\left(\frac{\mu}{b}\right)\left\{\operatorname{Re}\left[\sum_{n=1}^{\infty}\left(\frac{1}{i \pi n}\right) U\left(x, \frac{2 n \pi}{T} ; \xi_{k}, \eta_{k}\right) e^{2 i n n t / T}\right]\right. \\
\left.-\frac{1}{2} S(t)\left[\operatorname{sgn}\left(x-\xi_{k}\right)-\operatorname{sgn}\left(x-\eta_{k}\right)\right]\right\}
\end{gathered}
$$

(again, the infinite sum is rearranged in practice). Here sgn $(x)=+1$ for $x>0$, and $\operatorname{sgn}(x)=-1$ for $x<0$. When the 
constraint of (B11) is recognized, we have

$$
\begin{aligned}
\tau_{i}^{\prime}(x, t)=V_{p i} T \sum_{k=0}^{8} F_{k}(x, t) \\
\quad-\sum_{k=1}^{8} \sum_{j=1}^{39} \Delta_{k j}\left[F_{k}(x, t)-F_{k}\left(x, t-t_{j}\right)\right]
\end{aligned}
$$

where now only the $\Delta_{k j}$ of the preslip history enter. Of course, the first term here represents the solution without preslip, and the summation can be more simply evaluated in terms of the stress history $\tau_{t}^{\prime}(x, t)$ calculated from (B10) and shown in Figure 13.

In the preslip zone, $k=1-8$, we specify the time $\operatorname{step} j=$ $j_{*}(k)$ at which segment $k$ begins to slip. For example, the segment marked $A$ in Figure 16, which we call segment 1, begins at time $t=31 T / 40$, so $j_{*}(1)=31$; that marked $\mathrm{B}$, which we call segment 4 , begins at $t=34 T / 40$, so $j_{*}(4)=34$. Thus $\Delta_{k_{\lrcorner}}$ will be nonzero only for $j=j_{*}(k), j_{*}(k)+1, \cdots, 39$. The nonzero $\Delta_{k j}$ are chosen to maintain a fixed stress drop $\Delta t$. Thus we require that

$$
\tau_{t}^{\prime}\left(x_{k}, t_{j_{m}(k)}\right)-\tau_{i}^{\prime}\left(x_{k}, t_{j}^{+}\right)=\Delta \tau
$$

for each segment $k=1,2, \cdots, 8$ and for each time for $j=$ $j_{*}(k), j_{*}(k)+1, \cdots, 39$; here $x_{k}$ is the midpoint position of preslip segment $k$. Using (B16), this provides as many linear equations as there are unknowns of the preslip history $\Delta_{k j}$. We solve these equations numerically for the $\Delta_{k j}$ and insert the results into (B13) and (B16) to compute the stress histories shown in Figures 17-20.

Acknowledgments. This study was supported by USGS grants 14 01-0001-G1203 and G1367 and by NSF grants EAR84-11201 and 86-18080. We are grateful for discussions with $\mathrm{K}$. McNally, in the early stages of the work, on Middle American Trench seismicity. Also, we are grateful to A. Dziewonski for help in the access to ISC data and centrold moment tensor solutions and to J. Kurland for checking the mathematics and programming. Careful comments by W. Spence, W. D. Stuart, W. Thatcher, and two anonymous reviewers helped to improve the test.

\section{REFERENCES}

Astiz, L., and H. Kanamori, Interplate coupling and temporal variation of mechanisms of intermediate-depth earthquakes in Chile, Bull. Seismol. Soc. Am., 76, 1614-1622, 1986.

Beck, S., and L. Ruff, Seismicity and subduction along the Peru trench (abstract), Eos Trans. AGU, 65, 998, 1984.

Bischke, R. E., A model of convergent plate margins based on the recent tectonics of Shikoku, Japan, J. Geophys. Res., 79, 4845-4857, 1974.

Chapple, W. M., and D. W. Forsyth, Earthquakes and bending of plates at trenches, J. Geophys. Res., 84, 6729-6749, 1979.

Chen, T., and D. W. Forsyth, A detailed study of two earthquakes seaward of the Tonga trench: Implications for mechanical behavior of the oceanic lithosphere, J. Geophys. Res., 83, 4995-5003, 1978.

Christensen, D. H., and L. J. Ruff, Outer-rise earthquakes and seismic coupling, Geophys. Res. Lett., 10, 697-700, 1983.

Dewey, J. W., and W. Spence, Seismic gaps and source zones of recent large earthquakes in coastal Peru, Pure Appl. Geophys., 117, 1148$1171,1979$.

Dmowska, R., and B. V. Kostrov, A shearing crack in a semi-space under plane strain conditions, Arch. Mech., 25, 421-440, 1973.

Dmowska, R., and L. C. Lovison, Intermediate term seismic precursors for some coupled subduction zones, Pure Appl. Geophys., 126, 643-664, 1988.

Dmowska, R., L. Lovison, and J. R. Rice, Stress accumulation and transfer between a subduction slab and the thrust contact zone during the whole earthquake cycle (abstract), Eos Trans. AGU, 67, 307, 1986.

Dziewonski, A. M., and J. H. Woodhouse, An experiment in systematic study of global seismicity: Centroid-moment tensor solutions for 201 moderate and large earthquakes of 1981, J. Geophys. Res., $88,3247-3271,1983$.

Fedotov, S. A., Regularities of the distribution of strong earthquakes in Kamchatka, the Kurile Islands, and northern Japan, Tr. Inst. Phys. Earth Acad. Sci. USSR, 36, 66-93, 1965.

Fitch, T. J., and C. H. Scholz, Mechanism of underthrusting in southwest Japan: A model of convergent plate interactions, J. Geophys. Res., 76, 7260-7292, 1971.

Forsyth, D. W., Determination of focal depths of earthquakes associated with the bending of oceanic plates at trenches, Phys. Earth Planet. Inter., 28, 141-160, 1982.

Gonzalez, J., K. C. McNally, E. D. Brown, and K. Bataille, The whole earthquake cycle of the Middle American Trench, offshore Mexico (abstract), Eos Trans. AGU, 65, 998, 1984.

Kelleher, J. A., Space-time seismicity of the Alaska-Aleutian sessmic zone, J. Geophys. Res., 75, 5745-5756, 1970.

Kelleher, J. A., Rupture zones of large South American earthquakes and some predictions, J. Geophys. Res., 77, 2087-2103, 1972.

Kelleher, J. A., L. Sykes, and J. Oliver, Possible criteria for predicting earthquake locations and their applications to major plate boundaries of the Pacific and the Caribbean, J. Geophys. Res., 78, 2547$2585,1973$.

Korrat, I., and R. Madariaga, Rupture of Valparaiso (Chile) gap from 1971 to 1985, in Earthquake Source Mechanics, Geophys. Monogr. Ser., vol. 37, edited by S. Das, J. Boatwright, and C. H. Scholz, pp. 247-258, AGU, Washington, D. C., 1986.

Lehner, F. K., and V. C. Li, Large-scale characteristics of plate boundary deformations related to the post-seismic readjustment of a thin asthenosphere, Geophys. J. R. Astron. Soc., 71, 775-792, 1982.

Lehner, F. K., V. C. Li, and J. R. Rice, Stress diffusion along rupturing plate boundaries, J. Geophys. Res., 86, 6155-6169, 1981

$\mathrm{Li}$, V. C., and J. R. Rice, Preseismic rupture progression and great earthquake instabilities at plate boundaries, J. Geophys. Res., 88, $4231-4246,1983$

$\mathrm{Li}$, V. C., and J. R. Rice, Crustal deformation in great California earthquake cycles, J. Geophys. Res., 92, 11,533-11,551, 1987.

Lovison, L. C., Seismicity variations throughout the Middle American Trench subduction earthquake cycle, M.A. thesis, Dep. of Earth and Planet. Sci., Harvard Univ., Cambridge, Mass., 1986.

Malgrange, M., and R. Madariaga, Complex distribution of large thrust and normal-fault earthquakes in the Chilean subduction zone, Geophys. J. R. Astron. Soc., 73, 489-505, 1983.

Malgrange, M., A. Deschamps, and R. Madariaga, Thrust and extensional faulting under the Chilean coast: 1965, 1971 Aconcagua earthquakes, Geophys. J. R. Astron. Soc., 66, 313-331, 1981.

McCann, W. R., S. P. Nishenko, L. R. Sykes, and J. Krause, Seismic gaps and plate boundaries: Seismic potential for major boundaries, Pure Appl. Geophys., 117, 1082-1147, 1979.

McNally, K. C., and J. R. Gonzalez-Ruiz, Predictability of the whole earthquake cycle and source mechanics for large $\left(7.0 \leq M_{w} \leq 8.1\right)$ earthquakes along the Middle American Trench offshore Mexico (abstract), Earthquake Notes, 57(1), 22, 1986.

McNally, K. C., J. R. Gonzalez-Ruiz, and C. Stolte, Seismogenesis of the 1985 great $\left(M_{w}=8.1\right)$ Michoacan, Mexico earthquake, Geophys. Res. Lett., 13, 585-588, 1986.

Melosh, H. J., and L. Fleitout, The earthquake cycle in subduction zones, Geophys. Res. Lett., 9, 21-24, 1982.

Melosh, H. J., and A. Raefsky, Anelastic response of the Earth to a dip-slip earthquake, J. Geophys. Res., 88, 515-526, 1983.

Mogi, K., Some features of recent seismic activity in and near Japan, 2, Activity before and after great earthquakes, Bull. Earthquake Res. Inst. Univ. Tokyo, 47, 395-417, 1969.

Mogi, K., Two kinds of seismic gaps, Pure Appl. Geophys., 117, 11721186,1979

Nur, A., and G. Mavko, Postseismic viscoelastic rebound, Science, I83, 204-206, 1974.

Ohtake, M., T. Matsumoto, and G. V. Latham, Seismicity gap near Oaxaca, southern Mexico as a probable precursor to a large earthquake, Pure Appl. Geophys., 115, 375-385, 1977.

Rice, J. R., The mechanics of earthquake rupture, in Physics of the Earth's Interior, edited by A. M. Dziewonski and E. Boschi, pp. 555-649, Italian Physical Society, North-Holland, Amsterdam, 1980.

Savage, J. C., A dislocation model of strain accumulation and release at a subduction zone, J. Geophys. Res., 88, 4984 4996, 1983.

Scholz, C. H., and T. Kato, The behavior of a convergent plate boundary: Crustal deformation in the South Kanto district, Japan, J. Geophys. Res., 83, 783-797, 1978. 
Shimazaki, K., Correlation between intraplate seismicity and interplate earthquakes in Tohoku, northeast Japan, Bull. Seismol. Soc Am., 68, 181-192, 1978.

Smith, A. T., Time-dependent strain accumulation and release at island arcs: Implications for the 1946 Nankaido earthquake, Ph.D. thesis, Mass. Inst. of Technol., Cambridge, 1974.

Spence, W., Slab pull and the seismotectonics of subducting lithosphere, Rev. Geophys., 25, 55-69, 1987.

Sykes, L. R., Aftershock zones of great earthquakes, seismicity gaps, and earthquake prediction for Alaska and the Aleutians, J. Geo phys. Res., 76, 8021-8041, 1971.

Thatcher, W., and J. B. Rundle, A model for the earthquake cycle in the underthrust zones, J. Geophys. Res., 84, 5540-5556, 1979.

Thatcher, W., and J. B. Rundle, A viscoelastic coupling model for the cyclic deformation due to periodically repeated earthquakes at subduction zones, J. Geophys. Res., 89, 7631-7640, 1984.

Tse, S. T., and J. R. Rice, Crustal earthquake instability in relation to the depth variation of frictional slip properties, J. Geophys. Res., 91 9452-9472, 1986

Utsu, T., Large earthquakes near Hokkaido and the expectancy of the occurrence of a large earthquake off Nemuro, Rep. 7, pp. 7-13, Coord. Comm. Earthquake Predict., Tokyo, 1972.

Ward, S. N., Body wave inversion: Moment tensors and depths of oceanic intraplate bending earthquakes, J. Geophys. Res., 88, 93159330, 1983.

Ward, S. N., A note on lithospheric bending calculations, Geophys. J. R. Astron. Soc., 78, 241-253, 1984.

R. Dmowska, D. Josell, L. C. Lovison, and J. R. Rice, Division of Applied Sciences, Harvard University, Cambridge, MA 02138.

(Received July 8, 1987;

revised March 8, 1988;

accepted March 10, 1988.) 